Article

\title{
Preferential Incorporation of Azelaic Acid Units into the Crystalline Phase of the Copoly(Alkylene Dicarboxylate) Derived from 1,9-Nonanediol and an Equimolar Mixture of Pimelic and Azelaic Acids
}

\author{
Angélica Díaz, María T. Casas and Jordi Puiggalí * \\ Chemical Engineering Department, Polytechnic University of Catalonia, Av. Diagonal 647, \\ Barcelona E-08028, Spain; E-Mails: angelicadiaz07@hotmail.com (A.D.); \\ m.teresa.casas@upc.edu (M.T.C.) \\ * Author to whom correspondence should be addressed; E-Mail: Jordi.Puiggali@upc.edu; \\ Tel.: +34-93-401-6684; Fax: +34-93-401-7150.
}

Academic Editor: Patrick Ilg

Received: 22 August 2015 / Accepted: 14 September 2015 / Published: 22 September 2015

\begin{abstract}
The crystalline structure of two biodegradable odd-odd polyesters (i.e., poly(nonamethylene pimelate) (PES 9,7) and poly(nonamethylene azelate) (PES 9,9)) was investigated by means of electron and X-ray diffraction of single crystals and oriented fibers, respectively. Truncated rhombic crystals were obtained with an aspect ratio that was strongly depended on the supercooling degree. The crystalline structure of both homopolyesters was defined by an orthorhombic $P 2{ }_{1} a b$ space group and a large unit cell containing four molecular segments with an all-trans conformation. Nevertheless, the structure in the chain axis projection was equivalent to a simpler cell containing only two segments. Crystalline lamellae were effectively degraded by lipases, starting the enzymatic attack on the lamellar surfaces. The random copolymer constituted by an equimolar amount of pimelate and azelate units (COPES 9,7/9) crystallized according to regular lamellae with a similar molecular arrangement in the chain axis projection. The structure of this copolymer was preferably conditioned by the azelate component as could be deduced from both, diffraction and spectroscopic data. Analysis of small angle X-ray scattering patterns pointed out that less crystalline lamellae with higher amorphous thickness had developed in the copolymer. This feature was interpreted as a consequence of the preferential incorporation of pimelate comonomer units in the folding surface.
\end{abstract}


Keywords: polyesters; poly(alkylene dicarboxylate)s; crystalline structure; lamellar crystals; pimelic acid; azelaic acid; enzymatic degradation; structure of copolyesters

\section{Introduction}

Poly(alkylene dicarboxylate)s constitute a family of biodegradable polymers with growing interest since the limitations caused by the moderate molecular weight usually attained by conventional thermal polycondensation methods [1] have been overcome by using chain extenders [2,3], new highly efficient catalysts [4-6] or even ring opening polymerizations [7,8]. Therefore, these polymers attract increasing attention in solving "white pollution" concerns caused by traditional non-biodegradable polymers and also for their use as speciality polymers in applications, mainly in the biomedical field [9].

Biodegradable poly(alkylene dicarboxylate)s derived from bio-based monomers have also an additional interest since they can reduce dependence on fossil resources. Typical examples correspond to polyesters having long linear polymethylenic segments which are directly prepared from fatty acids coming from plant oils [10,11]. Nevertheless, great efforts are also focused in achieving bio-based diols and dicarboxilic acids with shorter chain lengths as is the case of adipic acid, whose production could be achieved with engineered yeast strains by $\alpha$ - and/or $\omega$-oxidation of long-chain $n$-alkanes, alcohols, or fatty acid substrates [12]. Other well-known examples correspond to pimelic acid, obtained by oxidation of ricinoleic acid from castor oil, azelaic acid prepared by ozonolysis cleavage of the alkene double bond of oleic acid and subsequent oxidation and 1,9-nonanediol prepared by reduction of azelaic acid [13].

Synthesis of copoly(alkylene dicarboxylate)s offers a key opportunity to increase the range of degradable materials and even to get a set of new products with easily tuneable properties. Incorporation of comonomers has a great influence on the thermal and mechanical properties, sample crystallinity, and both hydrolitic and enzymatic degradability [14-16]. Noticeable studies refer to random copoly(alkylene dicarboxylate)s constituted by even units, and specifically representative examples are poly(butylene succinate-co-ethylene succinate) [17], poly(hexamethylene succinate-co-hexamethylene adipate) [18], poly(hexamethylene sebacate-co-hexamethylene adipate) $[19,20]$, and poly(hexamethylene suberate-co-hexamethylene adipate) [21].

Structural studies on poly(alkylene dicarboxylate)s indicate variability of molecular conformation and also a complex packing arrangement. Kink conformations can be found for example in polymers with a low number of methylene groups (e.g., poly(ethylene succinate) [22] and poly(butylene adipate) [23], whereas an extended conformation is usually postulated for polyesters with long polymethylene sequences [24,25].

Molecular packing of poly(alkylene dicarboxylate)s may be complex even for those with a simple extended zig-zag conformation. Electron diffraction patterns of such polyesters indicated that the unit cells projected along the chain axis were rectangular and contained only two molecular segments, the parameters being close to $a=0.500-0.504 \mathrm{~nm}$, and $b=0.73-0.75 \mathrm{~nm}$. However, recent works on some 1,4-butanediol [26] and 1,6-hexanediol [27] derivatives have revealed the existence of unit cells where the $b$-axis parameter was doubled. These more complex structures were characterized by the fact that neighbouring molecules along the $b$-axis were only equivalent in chain axis projection. 
Complex structures were also determined for poly(hexamethylene adipate) [28] and poly(hexamethylene succinate) [29] since the corresponding unit cells contained eight molecular segments. It should be pointed out that most of these structural studies involved diols and dicarboxylic acids with an even number of carbon atoms, as few reported data concern odd-odd polyesters as those involved in the present work.

Degradation of semicrystalline polymers preferably takes place in the amorphous phase but must also occur in the crystalline phases despite their closely-packed structure. Single lamellar crystals obtained by crystallization from dilute solutions are ideal systems to detect how hydrolytic and/or enzymatic degradation of these crystalline phases takes place. Therefore, extensive studies have been performed with single crystals of different polyesters [30,31] including poly(ethylene succinate) [32], poly(butylene adipate) [33] and poly(octamethylene suberate) [34]. In some cases, enzymatic attack was observed to occur preferentially on determined crystal sectors, suggesting that both molecular packing and the nature of molecular folds play a crucial role in the enzymatic degradation process [34].

The present work is focused on the study of the crystalline structure of poly(nonamethylene azelate) and poly(nonamethylene pimelate) homopolymers and the related copolymer constituted by an equimolar ratio of the two dicarboxylic units as examples of bio-based odd-odd poly(alkylene dicarboxylate)s. Furthermore, distribution of comonomer units in the crystalline phase of the random copolymer is evaluated as well as the repercussions on the single crystal morphology and the degradation behavior.

\section{Experimental Section}

\subsection{Synthesis of Poly(Alkylene Dicarboxylate)s}

All reagents and solvents were purchased from Sigma-Aldrich (Barcelona, Spain) and used without further purification.

Syntheses of poly(nonamethylene pimelate) (PES 9,7), poly(nonamethylene azelate) (PES 9,9), and poly(nonamethylene azelate-co-pimelate) (COPES 9,7/9) were carried out following a typical two-step polycondensation process (Figure 1). Basically samples were obtained by thermal polycondensation of an excess of 1,9-nonanediol (2.2:1 molar ratio) with azelaic acid, pimelic acid or an equimolar mixture. Titanium tetrabutoxide was used as a catalyst and the reaction was first performed in a nitrogen atmosphere at $150{ }^{\circ} \mathrm{C}$ for $6 \mathrm{~h}$ and then in vacuum at $180{ }^{\circ} \mathrm{C}$ for $18 \mathrm{~h}$. Polymers were purified by precipitation with ethanol of chloroform solutions (10 wt \%). Weight average molecular weights and polydispersity indices determined by GPC (Shimadzu, model LC-8A, Tokyo, Japan), using polymethyl methacrylate standards, were 19,600 g/mol and 2.47 for PES 9,7, 40,700 g/mol and 3.10 for PES 9,9, and $32,300 \mathrm{~g} / \mathrm{mol}$ and 2.40 for COPES 9,7/9 and samples.

Composition of the copolymer was corroborated from ${ }^{13} \mathrm{C}$ NMR spectra since vicinal carbons of the dicarboxylate units appeared well differentiated (i.e., 34.29 and $34.10 \mathrm{ppm}$ for azelate and pimelate units, respectively). Specifically the molar \% of pimelate units in the copolymer was $53 \%$. 


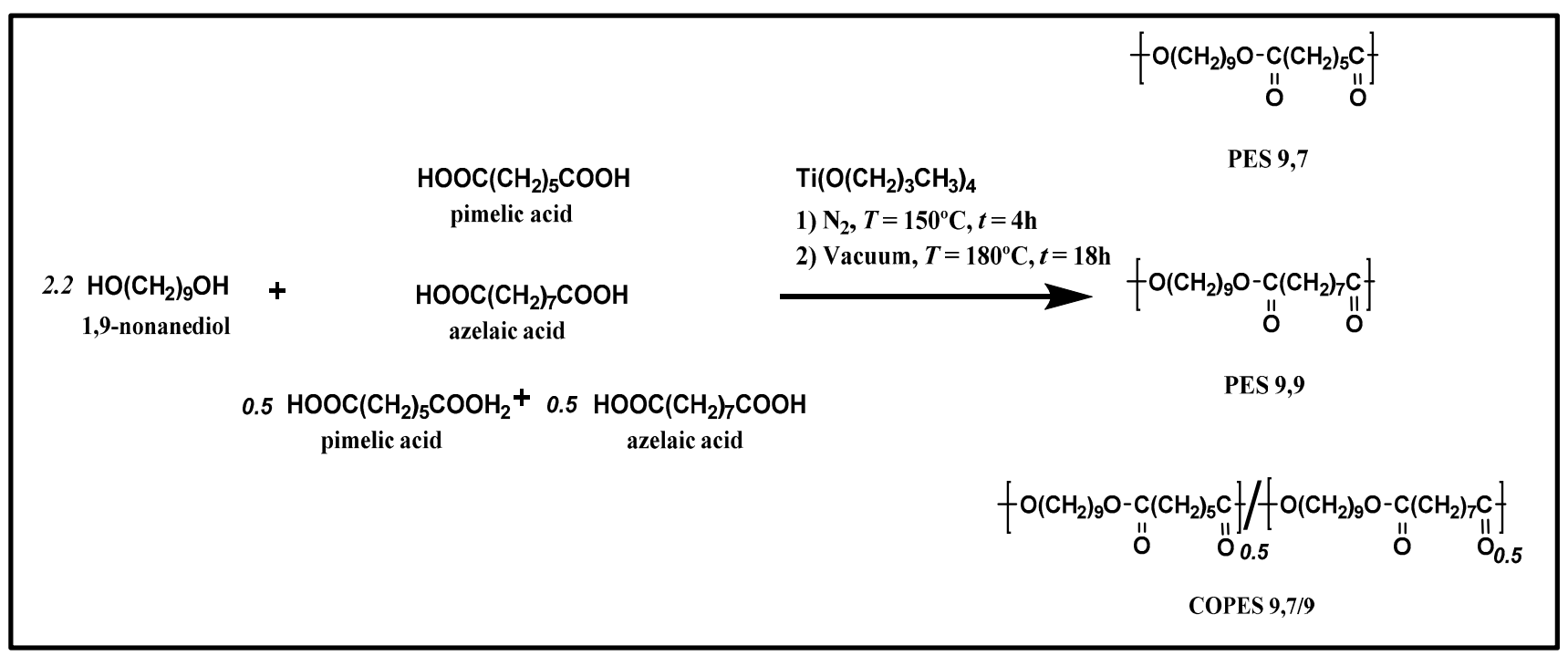

Figure 1. Synthesis of PES 9,7 and PES 9,9 homopolyesters and COPES 9,7/9 copolyester.

\subsection{Measurements}

Molecular weights were estimated by GPC using a liquid chromatograph (Shimadzu, model LC-8A, Tokyo, Japan) equipped with an Empower computer program (Waters, Milford, MA, USA) and a refractive index detector. A PL HFIP gel guard precolumn and PL HFIP gel column (Agilent Technologies Deutschland GmbH, Böblingen, Germany) were employed. The polymer was dissolved and eluted in 1,1,1,3,3,3-hexafluoroisopropanol at a flow rate of $0.5 \mathrm{~mL} / \mathrm{min}$ (injected volume $100 \mu \mathrm{L}$, sample concentration $1.5 \mathrm{mg} / \mathrm{mL}$ ). The number and weight average molecular weights were calculated using polymethyl methacrylate standards.

Infrared absorption spectra were recorded with a Fourier Transform FTIR 4100 Jasco spectrometer (Jasco International Co. Ltd., Tokyo, Japan) in the 4000-600 $\mathrm{cm}^{-1}$ range. A Specac model MKII Golden Gate attenuated total reflection (ATR) with a heated Diamond ATR Top-Plate (Specac, UK) was used. Absorbance measurements were determined from the area of the corresponding peaks after defining the baseline with the software program of the FTIR equipment. In order to avoid overlapping problems, the spectra of the random copolymer or the mixture of homopolymers were deconvoluted using the PeakFit v4 program by Jandel Scientific Software (Chicago, IL, USA).

${ }^{13} \mathrm{C}$ NMR spectrum was acquired with a Bruker AMX-300 spectrometer (Bruker Co., Bremen, Germany) operating at 75.7 MHz. Chemical shifts were calibrated using tetramethylsilane as an internal standard. Deuterated chloroform was used as the solvent.

Calorimetric data were obtained by differential scanning calorimetry with a TA Instruments Q100 series (TA Instruments, New Castle, DE, USA). Experiments were conducted at a heating rate of $20{ }^{\circ} \mathrm{C} / \mathrm{min}$ under a flow of dry nitrogen with a sample weight of approximately $10 \mathrm{mg}$. Calibration was performed with indium.

Lamellar crystals of the studied polyesters were obtained by isothermal crystallization in dilute $(0.50-0.25 \mathrm{mg} / \mathrm{mL})$ 1,6-hexanediol solutions at temperatures between 30 and $50{ }^{\circ} \mathrm{C}$. In all cases, the crystals were recovered from the mother liquor by centrifugation, repeatedly washed with $n$-butanol and 
deposited on carbon-coated grids, which were shadowed with Pt-Carbon at an angle of $15^{\circ}$ for bright field observations.

A Philips TECNAI 10 electron microscope (Philips Electron Optics, Eindhoven, The Netherlands) was used and operated at 80 and $100 \mathrm{kV}$ for bright field and electron diffraction modes, respectively. Selected area electron diffraction patterns and bright field micrographs were taken with a SIS MegaView digital camera (Olympus Soft Imaging Systems Inc., LLC, Lakewood, WA, USA). The diffraction patterns were internally calibrated with gold $\left(d_{111}=0.235 \mathrm{~nm}\right)$.

X-ray powder diffraction patterns were acquired with a PANalytical X'Pert diffractometer (Panalytical B.V. Almelo, The Netherlands) with $\mathrm{Cu} \mathrm{K} \mathrm{K}_{\alpha}$ radiation $(\lambda=0.1542 \mathrm{~nm})$ and a silicium monocrystal sample holder. Fiber diffraction patterns were collected with $\mathrm{Ni}$-filtered $\mathrm{Mo} \mathrm{K}_{\alpha}$ radiation of wavelength $0.0712 \mathrm{~nm}$ by a Mar Research 345 image plate detector. Oriented fiber and film samples were obtained by melt drawing.

Experimental fiber densities were calculated by the flotation method using ethanol and carbon tetrachloride as solvents. Values of 1.07, 1.06, and $1.03 \mathrm{~g} / \mathrm{mL}$ were obtained for PES 9,7, PES 9,9 and COPES 9,7/9 samples, respectively. Structural simulation was carried out with the diffraction software package of the Cerius 2 computer program (Accelrys Inc., Burlington, MA, USA) [35].

Polyester single crystals were degraded with lipases from Rhizopus oryzae (55.7 units/mg). Grids with deposited lamellar crystals were floated over $30 \mu \mathrm{L}$ of a pH 7.2 buffered medium of $50 \mathrm{mM}$ Tris- $\mathrm{HCl}$ and placed in a humid chamber at $40{ }^{\circ} \mathrm{C}$ for $10 \mathrm{~min}$. Grids were then laid over the degradation medium, which consisted of $30 \mu \mathrm{L}$ of the above buffered solution containing $2.2 \mathrm{mg} / \mathrm{mL}$ of the enzyme, and placed in the chamber under the above conditions for $3 \mathrm{~h}$. After digestion, grids were successively washed in a Tris-HCl buffer, distilled water, and ethanol. A Pelco pad with 40 concave recesses (diameter of $4.5 \mathrm{~mm}$ and depth of $1.5 \mathrm{~mm}$ ) was used throughout the whole protocol.

SAXS diffraction pattern were taken at the NCD beamline (BL11) of the Alba synchrotron radiation light facility of Cerdanyola del Valles (Catalunya). The beam was monochromatized to a wavelength of $0.098 \mathrm{~nm}$ and the samples were confined between Kapton films. Samples were held above fusion for 3 min to erase thermal history before performing a subsequent cooling run at a rate of $3{ }^{\circ} \mathrm{C} / \mathrm{min}$ after which SAXS diffraction patterns were taken. The SAXS detector was calibrated with different orders of diffraction from silver behenate. The diffraction profiles were normalized to the beam intensity and corrected considering the empty sample background. The correlation function and corresponding parameters were calculated with the CORFUNC program for Fibre Diffraction/Non-Crystalline Diffraction provided by the Collaborative Computational Project 13.

\section{Results and Discussion}

\subsection{Morphology of Single Crystals of PES 9,7, PES 9,9, and COPES 9,7/9 Samples}

Lamellar crystals of both PES 9,7 and PES 9,9 homopolyesters were obtained by isothermal crystallization in dilute diol solutions and a narrow temperature range (i.e., $30-50{ }^{\circ} \mathrm{C}$ ). This range was limited due to the relatively low melting point of the considered polyesters (i.e., $65-66{ }^{\circ} \mathrm{C}$ ) and the degree of supercooling that was necessary to get feasible nucleation and crystal growth processes. Our best results were specifically attained using 1,6-hexanediol since isolated crystals with large dimensions were predominant in the considered temperature interval for both samples. 
Morphology of single crystals was clearly dependent on the crystallization temperature as shown in Figure 2 for PES 9,7. Thus, irregular crystals became predominant at the lowest assayed crystallization temperature (i.e., $30{ }^{\circ} \mathrm{C}$ ) as a consequence of a microsectorization derived from the increased instability of the characteristic growth faces (Figure 2a). This feature is typical of high degrees of supercooling where the diffusion of molecules to the growth front controls the crystallization process in such a way that leads to the formation of dendrites [36].
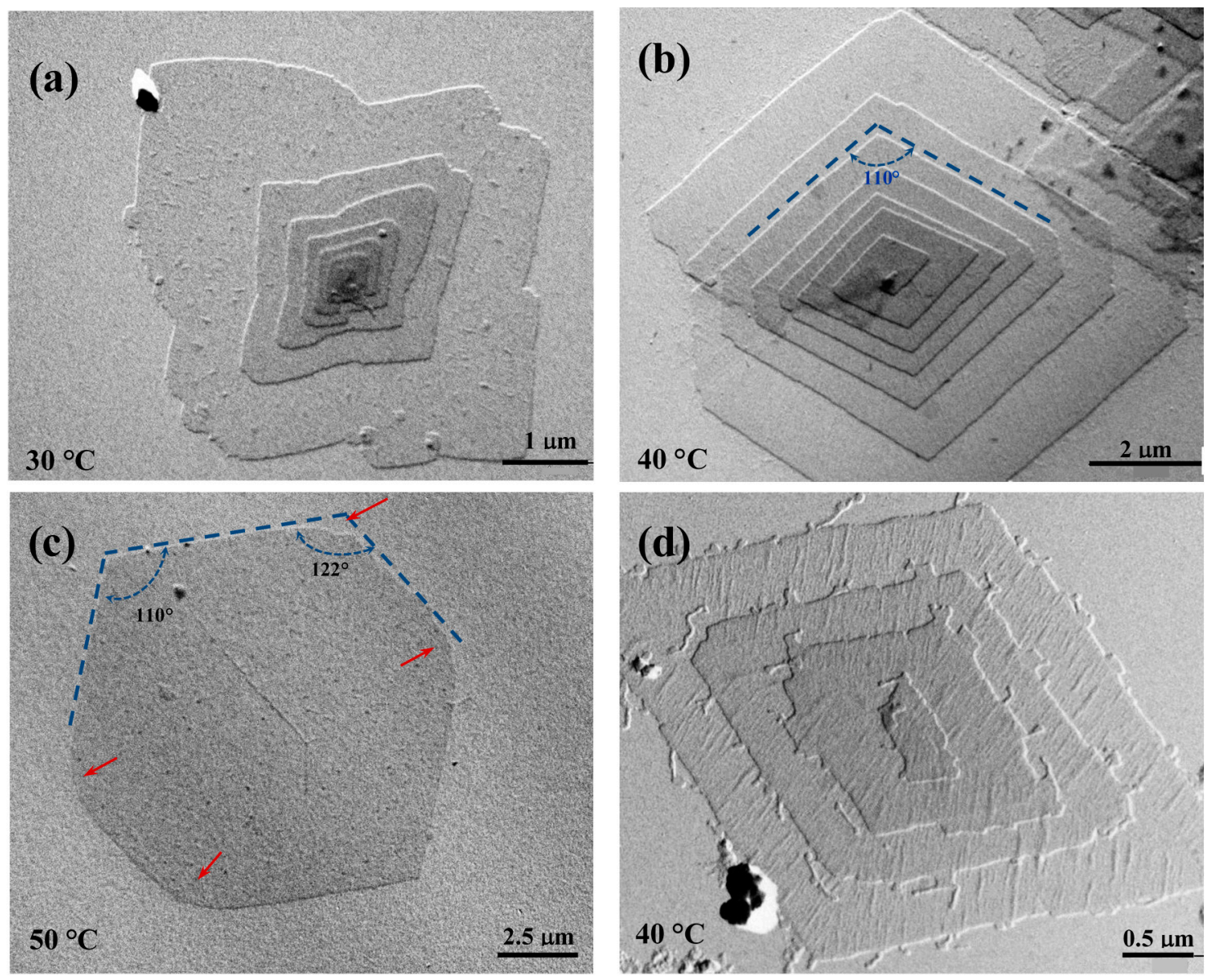

Figure 2. Transmission electron micrographs showing lamellar crystals of PES 9,7 crystallized from 1,6-hexanediol at $30{ }^{\circ} \mathrm{C}(\mathbf{a}) ; 40{ }^{\circ} \mathrm{C}(\mathbf{b}, \mathbf{d})$; and $50{ }^{\circ} \mathrm{C}(\mathbf{c})$.

A slight increase of temperature led to highly regular lamellar crystals with a lozenge morphology, with the angle between the most developed growth faces (i.e., the $\{110\}$ faces as will be explained) close to $110^{\circ}$ (Figure $2 \mathrm{~b}$ ). In general, slightly truncated multi-layered crystals were observed, with the thickness of each individual layer being between 1.0 and $1.3 \mathrm{~nm}$ as deduced from the corresponding shadows. Lamellar overgrowths usually emanated from right and left handed helical dislocations, which appeared in a similar ratio as expected from the achiral molecular structure. The face dimension of the basal crystal usually reached a maximum value close to $5 \mu \mathrm{m}$. Terrace growths (Figure 2d) were also frequently observed under these experimental conditions, with clearly detected crystallographic coherence between successive layers (i.e., no rotation was observed between crystals that appeared in a crystallographic register). 
Isolated and well developed lamellae were frequently found when the crystallization temperature was raised to $50{ }^{\circ} \mathrm{C}$. The lateral habit changed significantly and a close to hexagonal morphology was derived (Figure 2c). Therefore, the length of the truncated faces increased with crystallization temperature although at $50{ }^{\circ} \mathrm{C}$ was still shorter than that measured for the $\{110\}$ faces. Figure $2 \mathrm{c}$ shows also that the $\{110\}$ faces tend to curve (see red arrows) on approaching the truncated faces. Nevertheless, an angle close to $122^{\circ}$ could be estimated between $\{110\}$ and the truncated faces if this curvature was neglected.

Crystal growth faces became more irregular and frequent striations appeared on the lamellar surface (Figure 2d) when synthesized polymer samples were non-purified by precipitation (i.e., samples contained low molecular weight fractions). Striations highlighted the sectorization of crystals and always formed an angle between $60^{\circ}$ and $70^{\circ}$ with the $\{110\}$ growth faces. The origin of these defects is not clear although they have frequently been reported for different polyesters, requiring explanations based on the aggregation of microcrystals or the existence of different chain-packing states in the crystal.

Similar morphologic features were found in the crystallization experiments carried out with PES 9,9 (Figure 3). Angles between the predominant growth faces slightly changed to $112^{\circ}$ and $123^{\circ}$ as shown in Figure 3a. In general, truncation was favored for the azelate derivative since the pseudohexagonal morphology was reached at lower temperatures. Note the high similarity between single lamellar crystals obtained at $50{ }^{\circ} \mathrm{C}$ (Figure 2c) and $45^{\circ} \mathrm{C}$ (Figure 3a) with the pimelate and azelate derivatives, respectively. Differences concerning the degree of truncation are clearer when crystals prepared at $40{ }^{\circ} \mathrm{C}$ are compared (Figures $2 \mathrm{~b}$ and $3 \mathrm{~b}$ ).

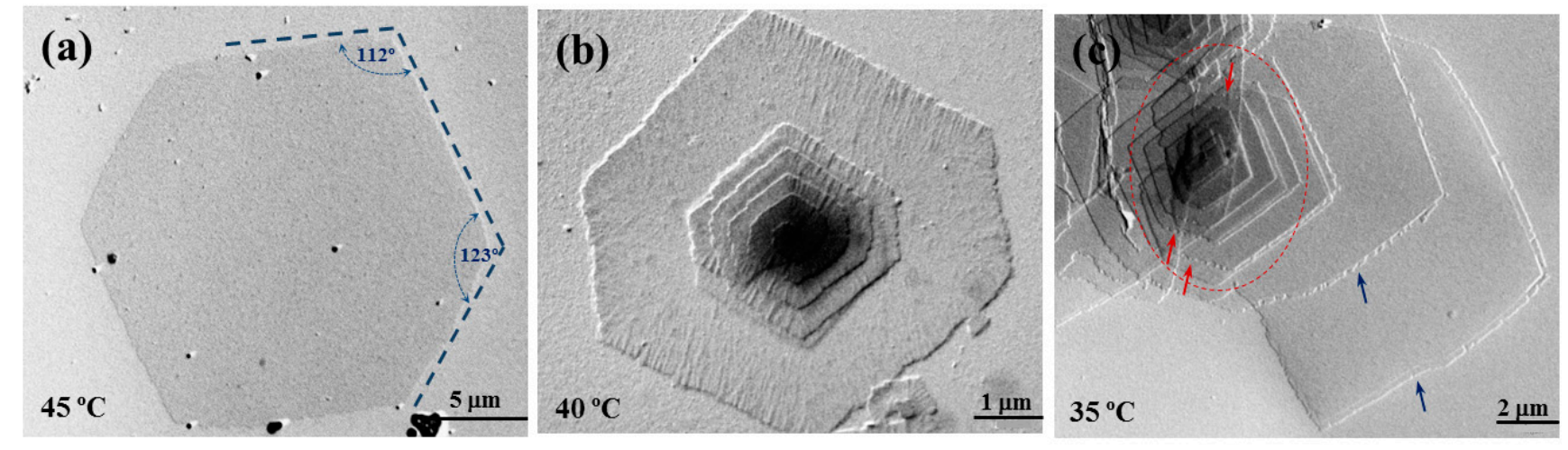

Figure 3. Transmission electron micrographs showing lamellar crystals of PES 9,9 crystallized from 1,6-hexanediol at $45^{\circ} \mathrm{C}(\mathbf{a}) ; 40^{\circ} \mathrm{C}(\mathbf{b})$; and $35^{\circ} \mathrm{C}(\mathbf{c})$.

Crystals of PES 9,9 showed also typical defects such as the presence of striations on the lamellar surface. These according to Figure $3 b$ seems to develop preferentially over the $\{110\}$ sectors. In addition, the $\{010\}$ growth faces tend to be serrated when the temperature decreased (e.g., down to $35{ }^{\circ} \mathrm{C}$ ) contrasting with the more regular growth that can still be detected for the $\{110\}$ faces. Figure $3 \mathrm{c}$ shows the presence of lozenge aggregates (inside the red ellipsoid) with even significantly developed truncated faces. In this case, the serrated morphology was clearly detected (see red arrows) since microsectorization was favored and the $\{010\}$ growth face became more instable. Large lamellae with non-well-defined crystalline habit, rounded faces and peculiar edges (e.g., see blue arrows in Figure 3c) were also detected in the different crystallizations. 
Results obtained from both homopolymers were in agreement with a decrease in the degree of truncation by decreasing the crystallization temperature (i.e., by increasing the supercooling degree). However, the differences between the single crystal morphology of homopolymers at a given temperature should be caused by a better solvent affinity of PES 9,9 since both homopolymers had a similar melting temperatures (i.e., 65.7 and $65.6^{\circ} \mathrm{C}$ determined from DSC experiments for azelate and pimelate derivatives, respectively).

Large single crystals of the random copolyester COPES 9,7/9 could also be prepared from 1,6-hexanediol dilute solutions despite its high comonomer content (i.e., 47 mol \%). Although melt crystallization of random poly(alkylene dicarboxylate)s have been extensively studied in recent years [16-22], this is the first time to our knowledge that single crystal morphology of such random copolymers has been evaluated. Figure 4a clearly shows pseudohexagonal lamellae of COPES 9,7/9 with identical morphology and dimensions to those crystals corresponding to the two homopolyesters that are shown in Figures $2 \mathrm{c}$ and $3 \mathrm{a}$. Note that angles of $110^{\circ}$ and $124^{\circ}$ could be measured between the characteristic faces of COPES 9,7/9 single crystals, a slight curvature can be detected in the $\{010\}-\{110\}$ face junction (red arrow) and the ratio between the lengths of these faces (i.e., $\left.d_{\{010\}} / d_{\{110\}}\right)$ was always close to 0.7 as could be also measured for the homopolyesters. It is interesting to note that this morphology was attained for the random copolymer at a remarkable lower temperature than for the homopolymers (i.e., $37{ }^{\circ} \mathrm{C}$ compared to $45-50{ }^{\circ} \mathrm{C}$ ) since it corresponds to a similar supercooling degree. Note that the melting temperature of the copolymer was significantly lower than determined for homopolyesters (i.e., $61.1^{\circ} \mathrm{C}$ compared to $65.6-65.7^{\circ} \mathrm{C}$ ). Figure $4 \mathrm{~b}$ precisely shows that elongated crystals with $d_{\{010\}} / d_{\{110\}}$ equal to 1.6 were typical of COPES $9,7 / 9$ crystals prepared at $47{ }^{\circ} \mathrm{C}$, which is in the middle of the temperature range $\left(45-50{ }^{\circ} \mathrm{C}\right)$ where the above mentioned PES 9,7 and PES 9,9 crystals with $d_{\{010\}} / \mathrm{d}_{\{110\}}$ equal to 0.7 were grown $\left(45-50{ }^{\circ} \mathrm{C}\right)$.
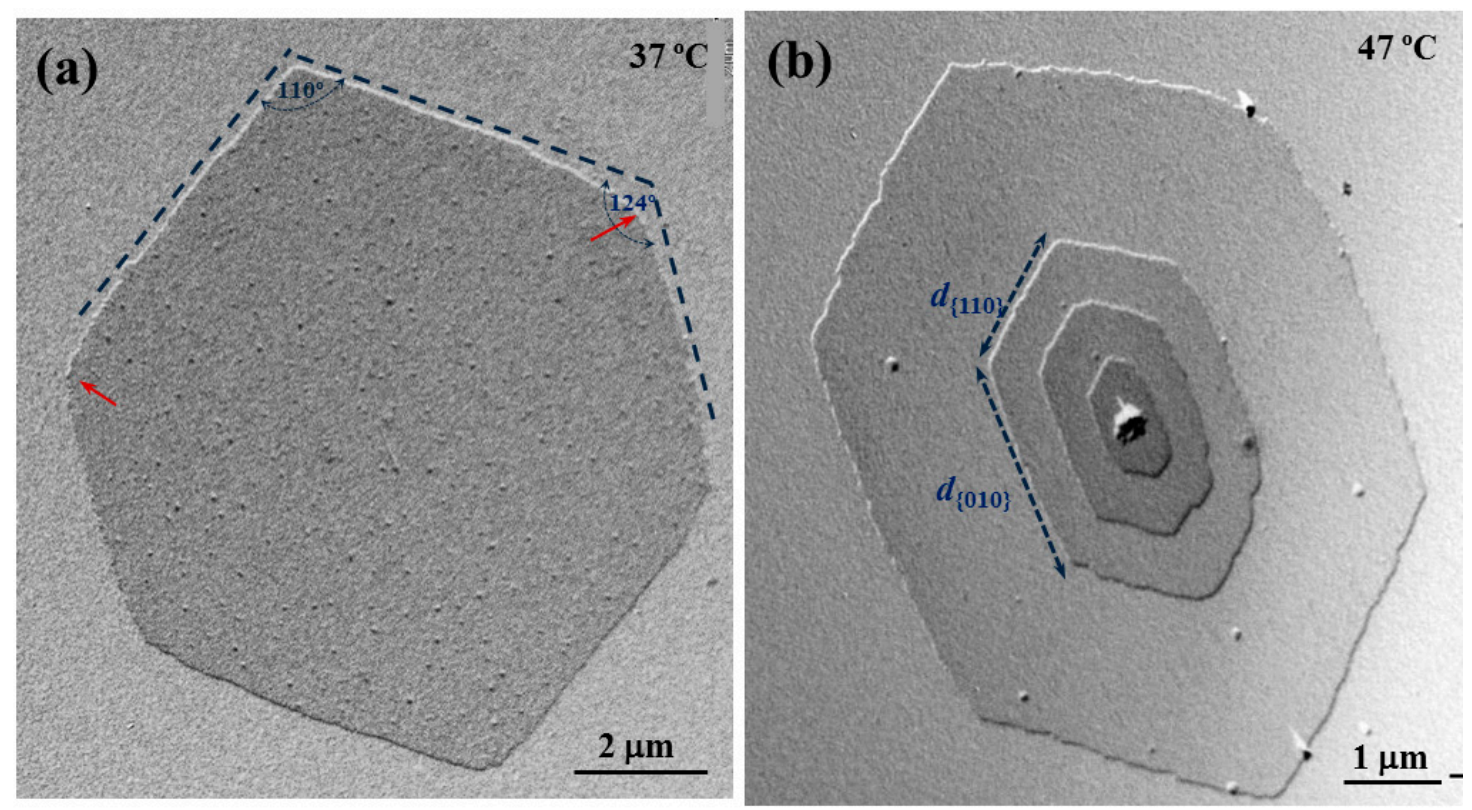

Figure 4. Transmission electron micrographs showing lamellar crystals of COPES 9,7/9 crystallized from 1,6 -hexanediol at $37^{\circ} \mathrm{C}$ (a) and $47^{\circ} \mathrm{C}(\mathbf{b})$. 
These clear differences between morphologies of copolymer and homopolymer crystals, developed at a given temperature, support a distinction at a molecular level as expected from random or blocky microstructures. Namely, crystals obtained from COPES 9,7/9 could not be a simple mixture of PES 9,9 and PES 9,7 crystals since in this case similar morphologies as found with homopolyesters should be observed. On the contrary, COPES 9,7/9 crystals seem truly derived from a random copolymer and consequently both azelate and pimelate units should be incorporated into lamellae without provoking a significant distortion of the crystalline lattice as can be explained from diffraction data analysis. Nevertheless, it is possible that azelate and pimelate comonomer units were differently distributed between the lamellar core and the lamellar surface. This observation means that the crystalline part may correspond mainly to one of the two homopolyester structures and therefore the observed regular and well-formed crystals could be better justified. The foreign comonomer units should be in this case preferentially incorporated onto the amorphous lamellar surface despite some proportion also being found in the dominant crystalline structure.

COPES 9,7/9 single crystals may also show the typical irregularities previously described for samples of homopolymers as depicted in Figure 5. Note for example that the spiral growth of lamellar crystals shown in Figure 5a is characterized by the presence of irregular edges and specifically the truncated faces appeared highly serrated as a consequence of the above indicated microsectorization. Striations on lamellar surfaces were also frequently observed (Figure 5b). Specifically, they appeared only on the $\{110\}$ sectors and formed an angle close to $45^{\circ}$ with the corresponding growth face. This value differs from the angle detected in PES 9,9 single crystals (Figure 3b), a feature that may suggest a different folding topology. Figure $5 \mathrm{~b}$ also shows the instability of the $\{010\}$ growth faces, which appeared again more serrated (blue arrow) or clearly curved (red arrow).
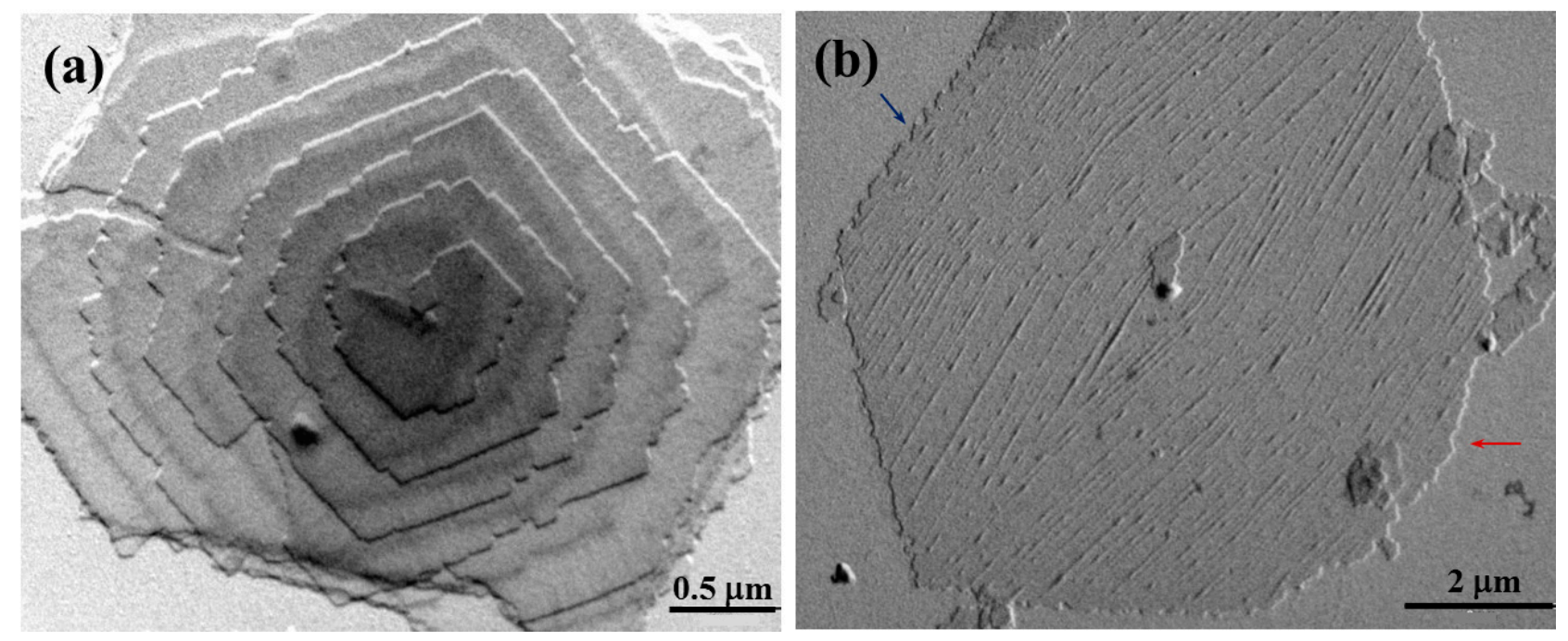

Figure 5. Transmission electron micrographs showing lamellar crystals of COPES 9,7/9 crystallized from 1,6-hexanediol at $37{ }^{\circ} \mathrm{C}$ having highly irregular $\{010\}$ faces (a) and frequent striations onto the lamellar surface (b). 
A single type of electron diffraction (ED) pattern was observed for both homopolyesters and even for the copolyester with similar azelate/pimelate ratio (Figure 6) despite the relatively wide range of assayed crystallization conditions and solvents. Polymorphism must therefore be discarded for the three studied samples. Electron diffraction patterns showed only $h k 0$ reflections and pointed out a typical molecular chain orientation perpendicular to the crystal basal plane. Consequently, a molecular folding can be inferred by considering the molecular weight of the samples and the relatively small lamellar thickness deduced from the crystal shadows.

(a)

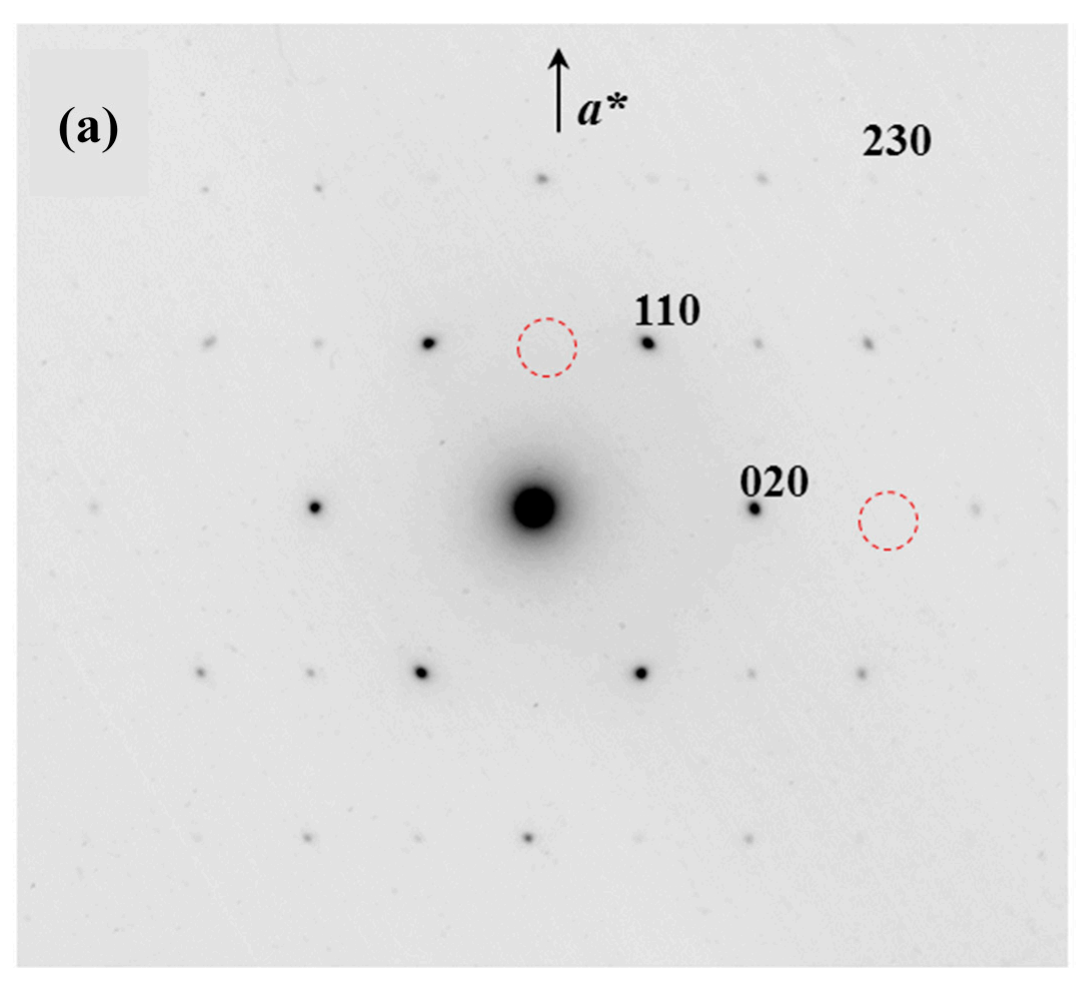

(b)

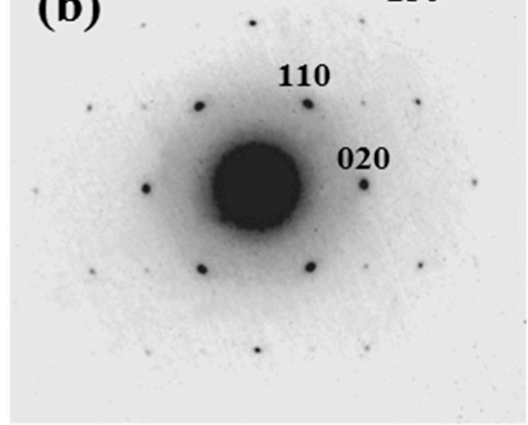

(c)

230

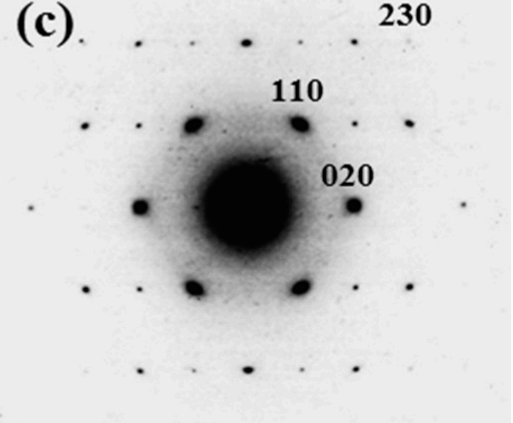

Figure 6. The $h k 0$ electron diffraction pattern of PES 9,7 (a); COPES 9,7/9 (b); and PES 9,9 (c) lamellar crystals obtained from 1,6-hexanediol solutions at crystallization temperatures of 50, 37, and $45^{\circ} \mathrm{C}$ for (a), (b) and (c), respectively. Systematic absences are observed for $h 00$ and $0 k 0$ reflections with odd values for the $h$ and $k$ indices as shown by the red dashed circles in (a).

All reflections observed in the ED patterns could always be indexed according to rectangular unit cells (Table 1) with dimensions similar to those of polyethylene and polyesters defined by an all-trans molecular conformation and a unit cell containing only two molecular chains. Thus, $a$ and $b$ parameters were close to 0.500 and $0.740 \mathrm{~nm}$, respectively. In all cases, the patterns were characterized by systematic $h 00$ and $0 k 0$ absences for odd $h$ and $k$ values that indicate the existence of translational symmetry elements. 
Table 1. Calculated and measured electron diffraction spacings $d$ (nm) for PES 9,7, PES 9,9, and COPES 9,7/9.

\begin{tabular}{ccccc}
\hline \multirow{2}{*}{ Index $^{\mathbf{a}}$} & $\boldsymbol{d}_{\text {calc }}$ & $\boldsymbol{d}_{\text {measured }}{ }^{\mathbf{b}}$ & $\boldsymbol{d}_{\text {measured }}{ }^{\mathbf{b}}$ & $\boldsymbol{d}_{\text {measured }}{ }^{\mathbf{b}}$ \\
\cline { 3 - 5 } & & PES 9,7 & PES 9,9 & COPES 9,7/9 \\
\hline 110 & 0.414 & $0.416 \mathrm{vs}$ & $0.413 \mathrm{vs}$ & $0.416 \mathrm{vs}$ \\
020 & 0.370 & $0.370 \mathrm{vs}$ & $0.370 \mathrm{vs}$ & $0.370 \mathrm{vs}$ \\
120 & 0.297 & $0.298 \mathrm{w}$ & $0.297 \mathrm{w}$ & $0.298 \mathrm{w}$ \\
200 & 0.250 & $0.247 \mathrm{~m}$ & $0.250 \mathrm{~m}$ & $0.247 \mathrm{~m}$ \\
210 & 0.234 & $0.233 \mathrm{vw}$ & $0.237 \mathrm{vw}$ & $0.233 \mathrm{vw}$ \\
130 & 0.221 & $0.222 \mathrm{~m}$ & $0.219 \mathrm{~m}$ & $0.222 \mathrm{~m}$ \\
220 & 0.207 & $0.208 \mathrm{w}$ & $0.208 \mathrm{w}$ & $0.208 \mathrm{w}$ \\
040 & 0.185 & $0.185 \mathrm{w}$ & $0.186 \mathrm{w}$ & $0.185 \mathrm{w}$ \\
230 & 0.176 & $0.176 \mathrm{vw}$ & $0.178 \mathrm{vw}$ & $0.176 \mathrm{vw}$ \\
310 & 0.163 & $0.162 \mathrm{vw}$ & $0.165 \mathrm{vw}$ & $0.163 \mathrm{vw}$ \\
\hline
\end{tabular}

${ }^{\mathrm{a}}$ On the basis of rectangular unit cells with parameters: $a=0.500 \mathrm{~nm}$ and $b=0.740 \mathrm{~nm} ;{ }^{\mathrm{b}}$ Abbreviations denote relative intensities: vs, very strong; s, strong; m, medium; w, weak; vw, very weak.

Correlation of bright field micrographs and selected area electron diffraction patterns indicates that single crystals were bounded by four $\{110\}$ faces with two truncated $\{010\}$ faces of variable dimensions, as aforementioned. The $\{110\}$ growth faces formed angles between $110^{\circ}$ and $112^{\circ}$, whereas a value close to $122-124^{\circ}$ was measured between the $\{110\}$ and $\{010\}$ faces. Both angles are in agreement with those calculated from the dimensions of the planar unit cells (i.e., 112 and $124^{\circ}$ ).

\subsection{Annealing and Degradation of Single Crystals}

Single crystals of the studied polyesters were obtained at temperatures very close to their dissolution temperature. Thus, solution-grown lamellae suspended in the selected solvent could be annealed in a very restricted temperature range (e.g., $55^{\circ} \mathrm{C}$ for the two homopolyesters and $50{ }^{\circ} \mathrm{C}$ for the copolyester). Figure 7a,c show lamellae of PES 9,7, as a representative sample, after being submitted to the indicated annealing process. Interestingly, framed crystals (see white arrows) were observed independently of the initial lamellar morphology (i.e., the slightly truncated rhombic crystals and the pseudohexagonal crystals obtained at $40{ }^{\circ} \mathrm{C}$ and $50{ }^{\circ} \mathrm{C}$, respectively) as a consequence of both a limited thickening, that only involved the crystal edges, and the complete dissolution of the thinner and inner part of the lamellae. At intermediate annealing times a partial dissolution was produced (Figure 7b) and holes were clearly detected inside the crystals while edges remained logically practically unaltered. 


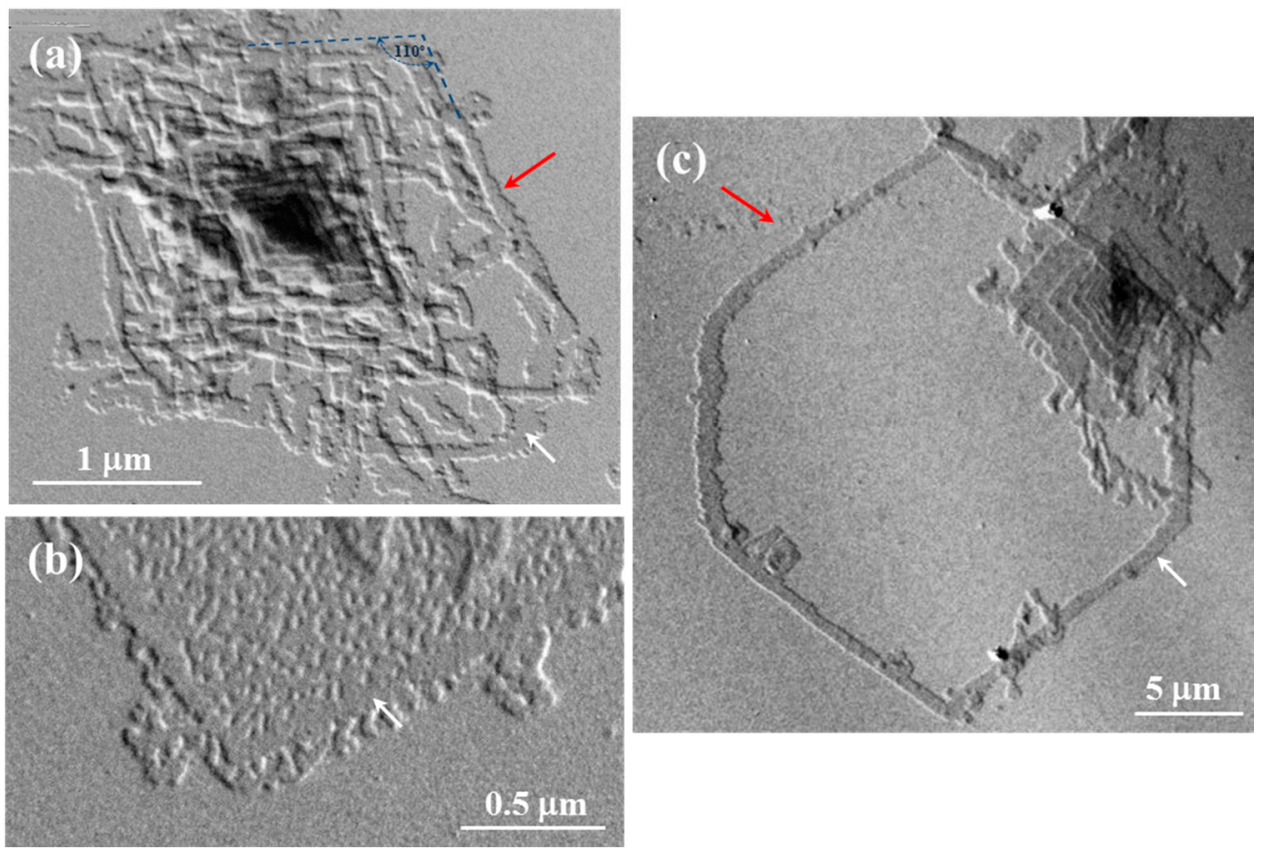

Figure 7. Transmission electron micrographs showing lamellar crystals of PES 9,7 crystallized from 1,6-hexanediol at $40{ }^{\circ} \mathrm{C}(\mathbf{a}, \mathbf{b})$ and $50{ }^{\circ} \mathrm{C}$ (c) after being kept for 3 (a,c) and 2 (b) days in the crystallization media at $55^{\circ} \mathrm{C}$. Red arrows point out the characteristic rhombic and pseudohexagonal crystals developed at each crystallization temperature. Note that only the corresponding frames can be observed after the annealing process.

Enzymatic degradation of polymer single crystals can be initiated by a fast attack at the chain folds in the amorphous lamellar surfaces to evolve subsequently at a slower rate when the dense lamellar core is reached. Alternatively or simultaneously, degradation can also be initiated from the crystal edges, leading to a systematic decrease of the crystal size in the lamellar plane. In some cases, lamellar sectors evidenced a different susceptibility to enzymatic attack, a feature that was related to the existence of distinct chain folds [34].

Enzymatic degradation of the lamellar crystals was followed in a lipase medium, a similar pattern for the studied copolyester and the two homopolymers being observed. Figure 8 shows the morphology of a representative pseudohexagonal crystal with well-developed $\{110\}$ and $\{010\}$ sectors after being exposed for $3 \mathrm{~h}$ to the degradation medium. Lamellar edges can be clearly detected despite the crystal being practically fully degraded, a feature that is in agreement with their high stability as deduced from annealing experiments. Enzymatic attack was therefore initiated in the lamellar surface giving rise to the complete dissolution of the inner part of the lamellae at the last stage of degradation. The selected enzyme was able to degrade the close packed crystalline region and furthermore did not show a preferential attack over the $\{110\}$ or $\{010\}$ sectors. In this way, the expected differences in the chain folding on the indicated sectors were not relevant for the studied samples. 


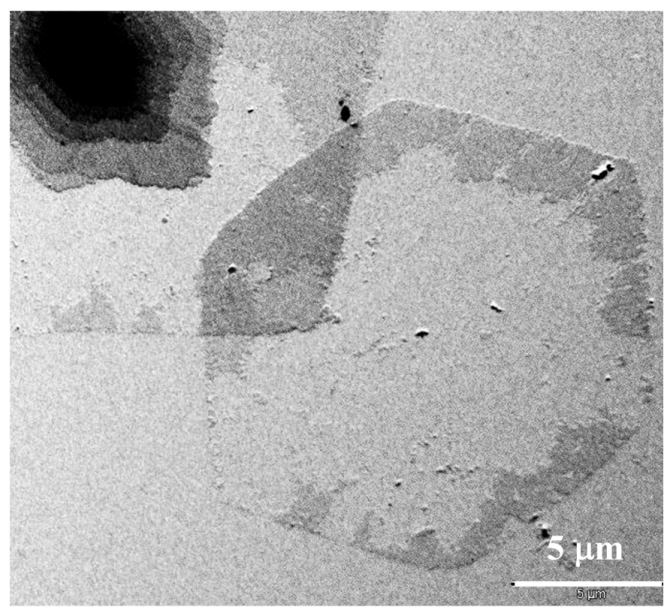

Figure 8. Transmission electron micrograph of PES 9,9 lamellar crystals crystallized from 1,6-hexanediol at $45^{\circ} \mathrm{C}$ and exposed for $3 \mathrm{~h}$ to the enzymatic degradation medium.

\subsection{X-ray Fiber Diffraction Data of PES 9,7, PES 9,9, and COPES 9,7/9 Samples}

X-ray diffraction patterns of annealed fibers of the two homopolymers showed a high degree of orientation (Figure 9). Reflections extended over a considerable number of layer lines and revealed some structural disorder along the chain axis. The weak streaks that can be detected in the different layer lines must be highlighted, although high intense and well defined spots were also characteristic for the 9th and 10th layer lines of PES 9,7 (i.e., $h k 9$ reflections) and PES 9,9 (i.e., $h k 10$ reflections), respectively. The high intensity of reflections appearing on these layer lines are related to the typical zig-zag nature of polymethylene chains with an extended conformation (i.e., $0.240-0.250 \mathrm{~nm}$ should correspond to the layer line spacing). In addition, close to meridional reflections on the 18th and 20th layer lines were also detected with high intensity due to the indicated zig-zag molecular conformation.

(a)

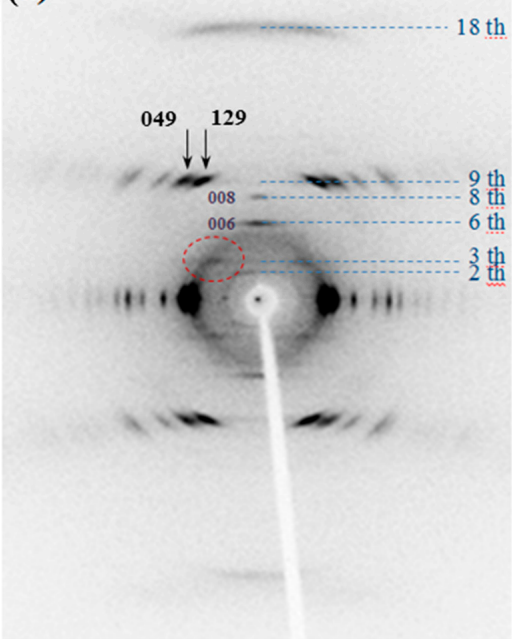

(b)

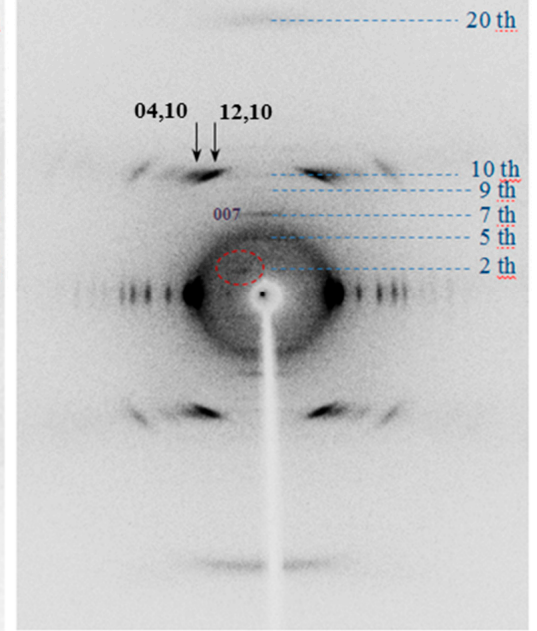

Figure 9. Fiber X-ray diffraction patterns of melt spun PES 9,7 (a) and PES 9,9 (b) fibers.

Patterns also show some well-defined meridional reflections that suggest an orthorhombic unit cell. Note the 006 and 008 reflections in the fiber pattern of PES 9,7 (Figure 9a) and the 005 and 007 reflections in the pattern of PES 9,9 (Figure 9b). Spacings of the indicated reflections pointed out chain axis 
periodicities close to 2.25 and $2.50 \mathrm{~nm}$ for the pimelate and azelate derivatives, respectively. These values are in full agreement with an all-trans molecular conformation and a chain axis periodicity that involves only one chemical repeat unit.

Strong $h k 0$ equatorial reflections appear at practically the same spacings (Table 2 ) as those appearing in electron diffraction patterns and consequently conventional polyester orthorhombic unit cells with $a$ and $b$ parameters close to 0.50 and $0.74 \mathrm{~nm}$, respectively can be postulated. Nevertheless, the streaks and the relatively weak reflections observed in some layer lines (see red circles in Figure 9) suggest a cell with greater dimensions as previously reported for some poly(alkylene dicarboxylate)s [26-29]. Note also that these off meridional reflections can clearly be detected in diffraction patterns recorded from oriented films due to their greater intensity (Figure 10). Specifically, significant reflections that agree with an orthorhombic lattice with a double $b$ axis parameter (i.e., $1.48 \mathrm{~nm}$ ) were detected and consequently the final indexing summarized in Table 2 is based on the larger unit cell. In addition, it should be indicated that medium-angle equatorial signals with superlattice values have also been reported for other polyester lamellar crystals, with in these cases a rippling nature to the fold surface suggested as a potential explanation [37,38].

The chain axis projected structures of the two studied odd-odd polyesters are highly similar considering the intensities of $h k 0$ reflections observed in the electron diffraction patterns and in the equator of the X-ray fiber patterns. Note also that the chain axis projection of the smaller $(b=0.74 \mathrm{~nm})$ and the larger unit $(b=1.48 \mathrm{~nm})$ cells should be equivalent.

Table 2. Calculated and measured fiber X-ray diffraction spacings $d$ (nm) for studied polyesters.

\begin{tabular}{cccccc}
\hline \multicolumn{3}{c}{ PES 9,7 } & \multicolumn{3}{c}{ PES 9,9 } \\
\hline Index $^{\mathbf{a}}$ & $\boldsymbol{d}_{\text {calc }}$ & $\boldsymbol{d}_{\text {measured }} \mathbf{b}$ & Index $^{\mathbf{c}}$ & $\boldsymbol{d}_{\text {calc }}$ & $\boldsymbol{d}_{\text {measured }} \mathbf{b}$ \\
\hline 120 & 0.414 & $0.416 \mathrm{vs} \mathrm{E}$ & 120 & 0.414 & $0.416 \mathrm{vs}$ \\
040 & 0.370 & $0.370 \mathrm{vs} \mathrm{E}$ & 040 & 0.370 & $0.370 \mathrm{vs}$ \\
140 & 0.297 & $0.298 \mathrm{w}$ & 140 & 0.297 & $0.298 \mathrm{w}$ \\
200 & 0.250 & $0.247 \mathrm{~m}$ & 200 & 0.250 & $0.247 \mathrm{~m}$ \\
220 & 0.234 & $0.233 \mathrm{vw}$ & 220 & 0.234 & $0.233 \mathrm{vw}$ \\
160 & 0.221 & $0.222 \mathrm{~m}$ & 160 & 0.221 & $0.222 \mathrm{~m}$ \\
240 & 0.207 & $0.208 \mathrm{w}$ & 240 & 0.207 & $0.208 \mathrm{w}$ \\
080 & 0.185 & $0.185 \mathrm{w}$ & 080 & 0.185 & $0.185 \mathrm{w}$ \\
260 & 0.176 & $0.176 \mathrm{vw}$ & 260 & 0.176 & $0.176 \mathrm{vw}$ \\
320 & 0.163 & $0.162 \mathrm{vw}$ & 320 & 0.163 & $0.163 \mathrm{vw}$ \\
006 & 0.375 & $0.373 \mathrm{~m}$ & 005 & 0.500 & $0.505 \mathrm{vw}$ \\
008 & 0.281 & $0.283 \mathrm{w}$ & 007 & 0.357 & $0.357 \mathrm{w}$ \\
129 & 0.214 & $0.214 \mathrm{~s}$ & 12,10 & 0.214 & $0.214 \mathrm{vs}$ \\
049 & 0.207 & $0.209 \mathrm{~s}$ & 04,10 & 0.207 & $0.209 \mathrm{~m}$ \\
149 & 0.191 & $0.192 \mathrm{w}$ & 14,10 & 0.191 & $0.194 \mathrm{vw}$ \\
229 & 0.172 & $0.170 \mathrm{~m}$ & 22,10 & 0.172 & $0.172 \mathrm{~m}$ \\
00,18 & 0.125 & $0.123 \mathrm{~m}$ & 00,20 & 0.125 & $0.122 \mathrm{~m}$ \\
\hline
\end{tabular}

${ }^{a}$ On the basis of rectangular unit cells with parameters: $a=0.500 \mathrm{~nm}, b=1.480 \mathrm{~nm}$ and $c=2.25 \mathrm{~nm}$ (chain axis); ${ }^{b}$ Abbreviations denote relative intensities and orientations: vs, very strong; s, strong; m, medium; w, weak; vw, very weak; E, equatorial; M, meridional; off M, off meridional; ${ }^{\mathrm{c}}$ On the basis of rectangular unit cells with parameters: $a=0.500 \mathrm{~nm}, b=1.480 \mathrm{~nm}$ and $c=2.50 \mathrm{~nm}$ (chain axis). 


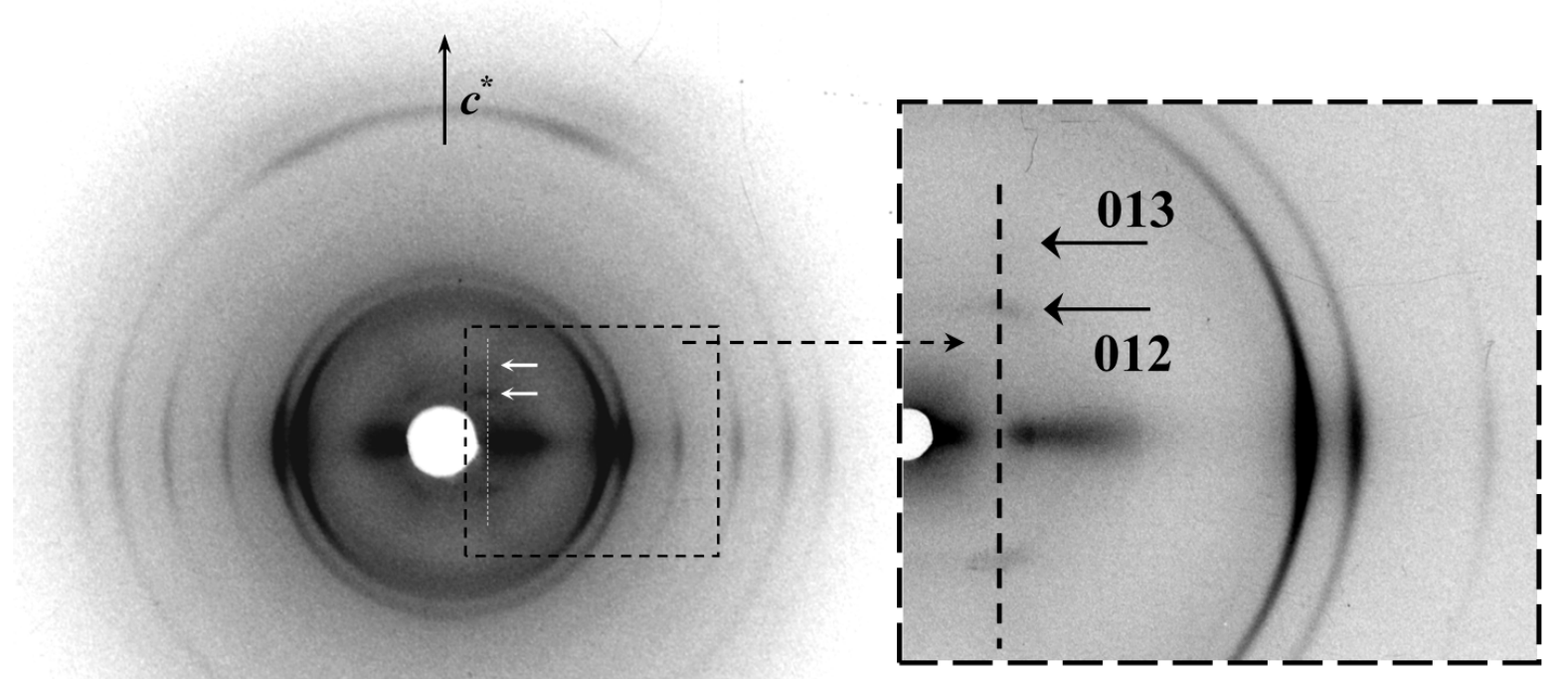

Figure 10. Fiber X-ray diffraction pattern of an oriented film of PES 9,9 with labelling of significant $01 l$ reflections. The inset corresponds to a low intensity pattern that allows the two strongest equatorial reflections to be distinguished at 0.414 and $0.370 \mathrm{~nm}$.

Reflections detected in the strong 9th and 10th layerlines of PES 9,7 and PES 9,9 showed a remarkable distinctive feature concerning their relative intensities. Thus, 129 and 049 reflections had relatively similar intensities whereas 12,10 reflection was clearly more intense than 04,10 (see arrows in Figure 9).

The measured densities of PES 9,7 and PES 9,9 fibers were $1.07 \mathrm{~g} / \mathrm{mL}$ and $1.06 \mathrm{~g} / \mathrm{mL}$, respectively, which were fairly close to the values calculated $(1.13$ and $1.12 \mathrm{~g} / \mathrm{mL})$ from the deduced cell dimensions and a cell content of four chain segments. Nevertheless, some amorphous content logically exists as can be inferred from the lower experimental densities.

Odd-odd polyester molecules displaying an all-trans conformation have a $2 \mathrm{~mm}$ molecular symmetry with binary axes perpendicular to the molecular chain through the middle of diol and dicarboxylic acid units. Only one chemical repeat unit is involved in the chain axis periodicity due to the lack of translational symmetry elements (e.g., $2_{1}$ screw axis or $c$ glide plane). These molecules have all carbonyl groups pointing in the same direction unlike even-even, odd-even, and even-odd polyesters. In a rough approximation molecular packing was simulated considering the $h k 0$ electron diffraction pattern and the single rectangular unit cell $(b=0.74 \mathrm{~nm})$ containing only two molecular segments related by a binary axis and having an all-trans molecular conformation (Figure 11). A relative good agreement between experimental and theoretical intensities was found for a setting angle close to $\pm 50^{\circ}$ with respect to the $a$ axis. 


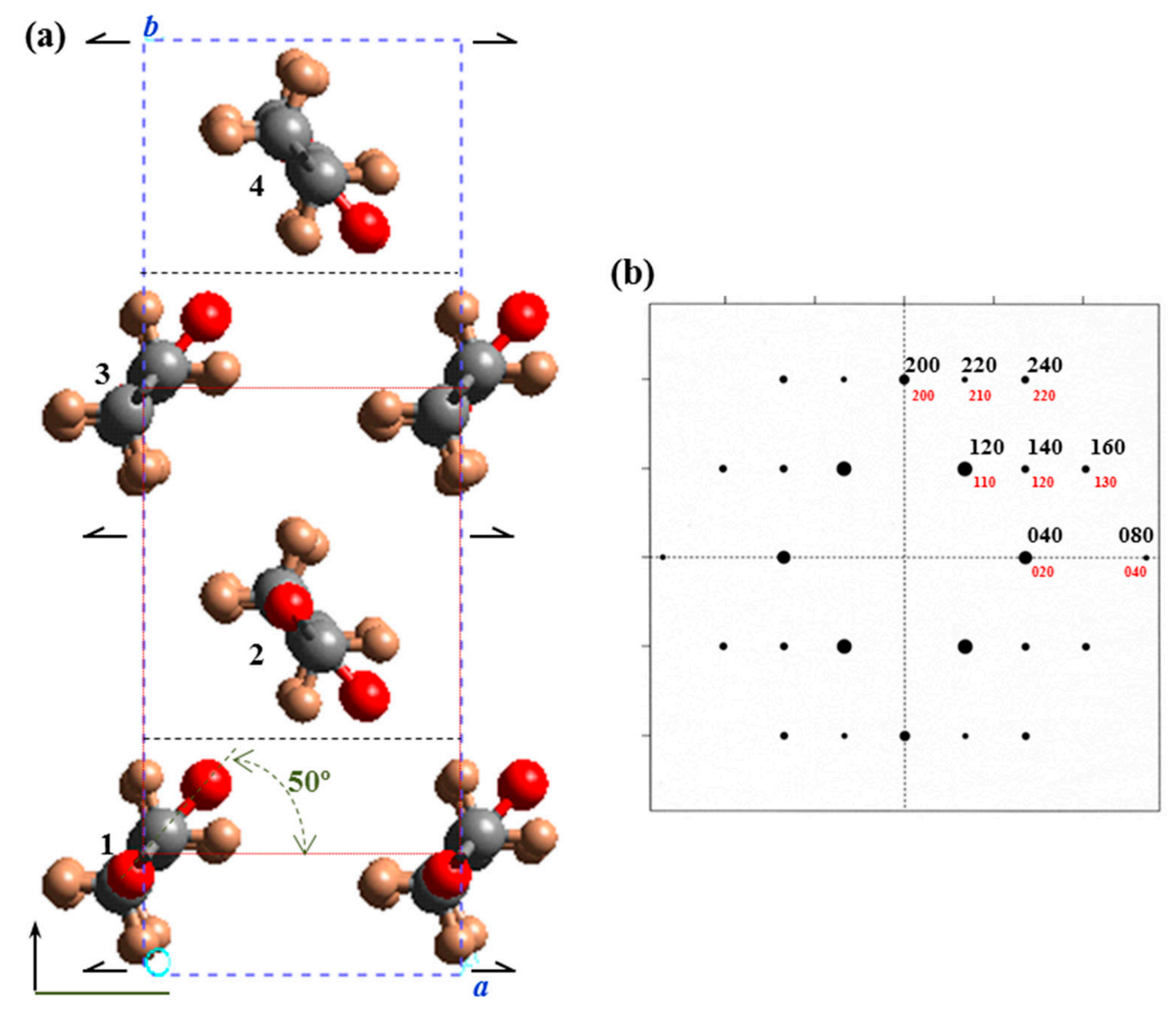

Figure 11. (a) Projection along the $c$-axis of the molecular packing of PES 9,7 defined by a $P 2{ }_{1} a b$ space group. For the sake of completeness the smaller unit cell containing only two molecular segments is also drawn (dotted red lines). Color code: Carbon, grey; oxygen, red; hydrogen, light brown. (b) Simulated $h k 0$ electron diffraction pattern for the crystalline structure of PES 9,7 defined by a molecular setting angle of $\pm 50^{\circ}$.

Fiber diffraction data and the observed systematic absences points out to a large unit cell $(b=1.48 \mathrm{~nm})$ and a $P 2{ }_{1} a b$ space group that implies a polar structure and allows the packing energy to be minimized by varying the chain axis shift between molecules 1 and 3 (Figure 11a). Note that this feature is not possible with the smaller cell ( $b=0.74 \mathrm{~nm}$ and $P 2{ }_{1} a m$ space group) since the indicated chains are not shifted. This restriction also precluded achieving a minimum concordance between simulated and experimental diffraction patterns when the small unit cells were considered.

Figure 12 shows the X-ray diffraction pattern of the COPES 9,7/9 copolymer. It is interesting to remark the well-defined $h k 0$ reflections that indicate an ordered arrangement in chain axis projection as expected from the regular lamellar crystals and the corresponding electron diffraction patterns. 


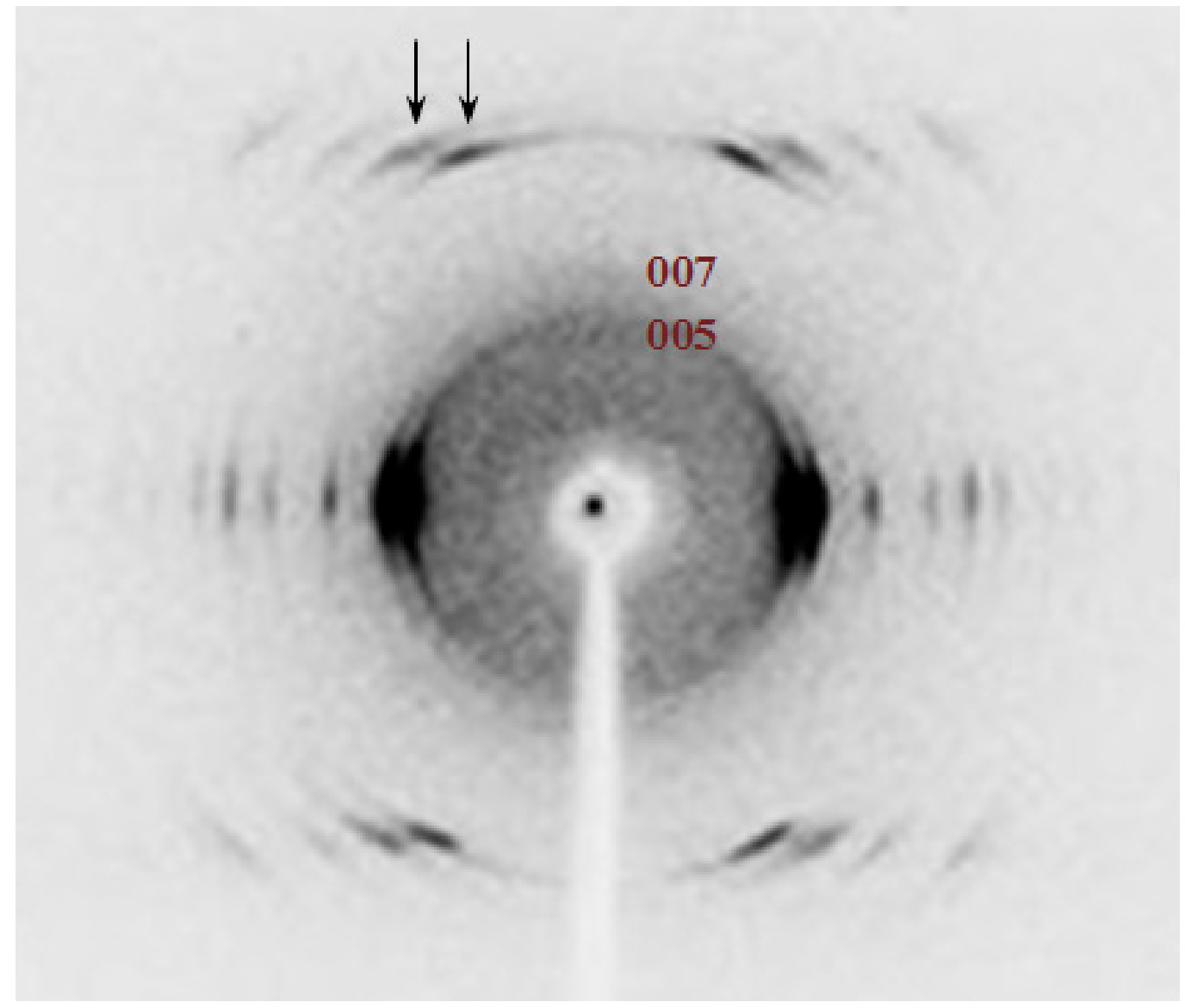

Figure 12. Fiber X-ray diffraction patterns of a melt spun COPES 9,7/9 fiber. Arrows point out the $12 l$ and $04 l$ reflections.

A disorder that concerns the disposition of molecular chains along the $c$ axis is also observed since $h k 0$ reflections of inner layer lines practically disappeared. Nevertheless, $00 l$ weak reflections at spacings of 0.500 and $0.375 \mathrm{~nm}$ (i.e., at similar values of 005 and 007 reflections of PES 9,9) could be detected suggesting that the copolymer structure was mainly determined by the azelate units. In the same way, the relative intensity between $12 l$ and $04 l$ reflections observed in the 9th or 10th strongest layerline (9th or 10th depending on which was the dominant structure) was closer to that determined for PES 9,9 (i.e., the $04 l$ reflection was much weaker than the $12 l$ reflection).

\subsection{FTIR Spectroscopic Data of PES 9,7, PES 9,9, and COPES 9,7/9 Samples}

The random copolyester COPES 9,7/9 easily crystallizes from the melt state, as revealed by the oriented fiber patterns, and also from dilute solutions giving rise as explained above to highly regular lamellar crystals. Diffraction data points towards a predominant crystalline structure defined by the azelate units, but results are not fully conclusive. Therefore, FTIR spectra were recorded since well differentiated bands could be associated to the crystalline structure of each homopolyester (Figure 13). 

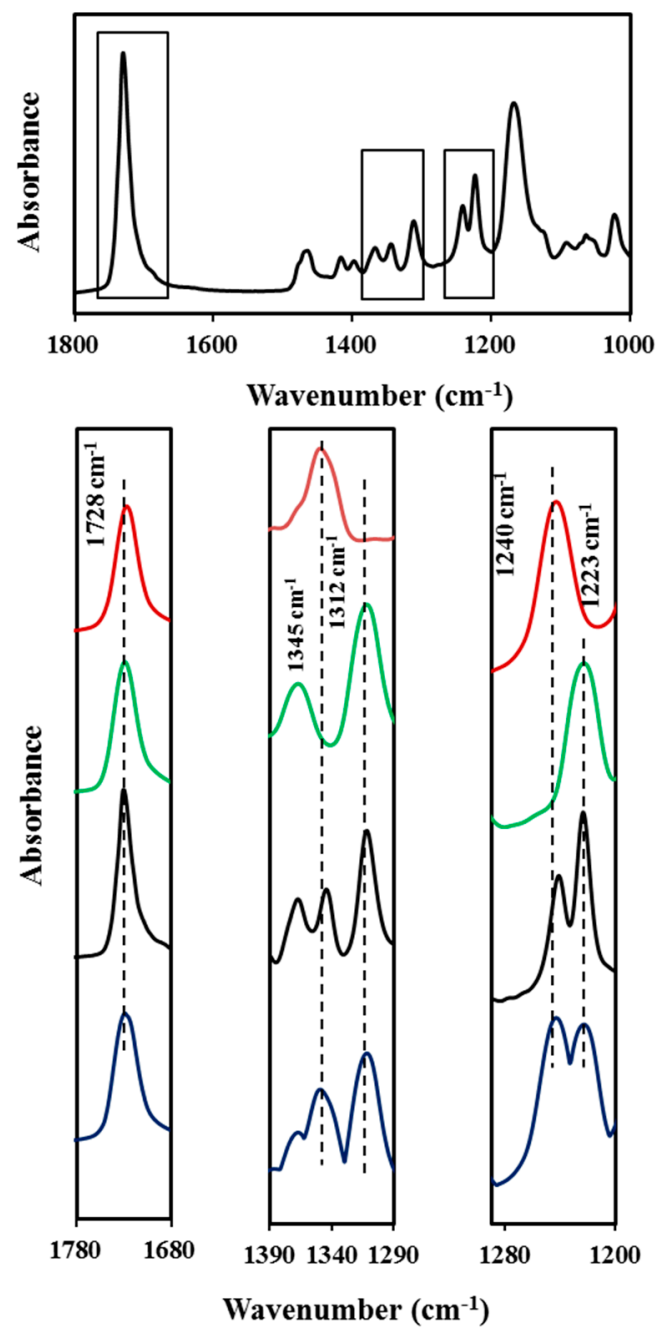

Figure 13. Absorbance FTIR spectra (1800-1000 $\mathrm{cm}^{-1}$ region) of COPES 9,7/9. Insets compare the common $\mathrm{C}=\mathrm{O}$ band at $1728 \mathrm{~cm}^{-1}$ (left), the characteristic bands for azelate and pimelate derivatives at 1345 and $1312 \mathrm{~cm}^{-1}$ (medium) and the characteristic bands at 1240 and $1223 \mathrm{~cm}^{-1}$ (right) for pimelate and azelate derivatives. Absorbance scale has been increased in the medium and right insets in order to show more clearly the different peaks. Profiles correspond to PES 9,7 (red), PES 9,9 (green), COPES 9,7/9 (black) and an equimolar mixture of PES 9,7 and PES 9,9 (blue).

The spectra of all samples was characterized by the very strong stretching band of the $\mathrm{C}=\mathrm{O}$ group at $1728 \mathrm{~cm}^{-1}$ that appeared in both semicrystalline and completely amorphous samples (i.e., in the spectra recorded at a temperature higher than the polymer melting point). However, the spectra of lamellar crystal samples of PES 9,7 and PES 9,9 have some distinctive and isolated bands that are only associated with crystalline domains and appear at different wavenumbers for each homopolymer. Thus, the 1345 and $1240 \mathrm{~cm}^{-1}$ bands seem characteristic of the pimelate derivative, whereas the 1312 and $1223 \mathrm{~cm}^{-1}$ bands are characteristic of the azelate derivative. For example, the asymmetric stretching band of the $\mathrm{C}-\mathrm{O}$ group seems clearly susceptible to small changes on the intermolecular interactions between neighboring chains (namely on slight differences between crystalline structure of both polyesters) and specifically varied from 1240 to $1223 \mathrm{~cm}^{-1}$. Absorbance ratios between the characteristic crystalline 
bands and the common band at $1728 \mathrm{~cm}^{-1}$ could be taken for further quantitative analyses. Thus, values of 0.15 and 0.30 were found for $A_{1345} / A_{1728}$ and $A_{1240} / A_{1728}$ ratios in the PES 9,7 spectrum, whereas values of 0.21 and 0.24 were determined for $A_{1312} / A_{1728}$ and $A_{1223} / A_{1728}$ ratios in the PES 9,9 spectrum. The indicated four crystalline bands were observed in the spectrum of the copolymer sample but PES 9,9 signals were more intense than expected for a crystalline sample having an equal content of azelate and pimelate units, as can be verified by comparison with the experimental spectrum of a mixture having a $50 \mathrm{~mol} \%$ of both homopolymers (Figure 13) and also from the values determined for the above indicated absorbance ratios. Thus, ratios involving PES 9,7 and PES 9,9 bands were smaller and greater, respectively than half the corresponding values determined for the homopolyesters. Specifically, $A_{1345} / A_{1728}$ and $A_{1240} / A_{1728}$ ratios were 0.055 and 0.11 (i.e., smaller than $0.15 / 2$ and $0.30 / 2$, respectively) and $A_{1312} / A_{1728}$ and $A_{1223} / A_{1728}$ ratios were 0.14 and 0.17 (i.e., greater than $0.21 / 2$ and $0.24 / 2$, respectively). These observations clearly point out that the lamellar core of the copolymer sample was predominantly constituted by azelate units (i.e., $65 \mathrm{~mol} \%$ instead of the theoretical value of $50 \mathrm{~mol} \%$ ) and that probably the pimelate units were mainly excluded in the amorphous lamellar surface.

\subsection{SAXS Data and Analysis of Correlation Function of PES 9,7, PES 9,9, and COPES 9,7/9 Samples}

\section{Crystallized from the Melt State}

In order to get insight into the lamellar structure SAXS peaks were analyzed by means of the correlation function that allowed morphologic parameters to be distinguished like: (a) long period, $L_{\gamma}$, (b) amorphous layer thickness, $l_{a}$, and (c) crystalline lamellar thickness, $l_{c}$, (calculated as $L_{\gamma}-l_{a}$ ). Therefore, the lamellar structure of polymers non-isothermally crystallized from the melt state at a cooling rate of $3{ }^{\circ} \mathrm{C} / \mathrm{min}$ was analyzed from the SAXS profiles taken at room temperature (Figure 14a).
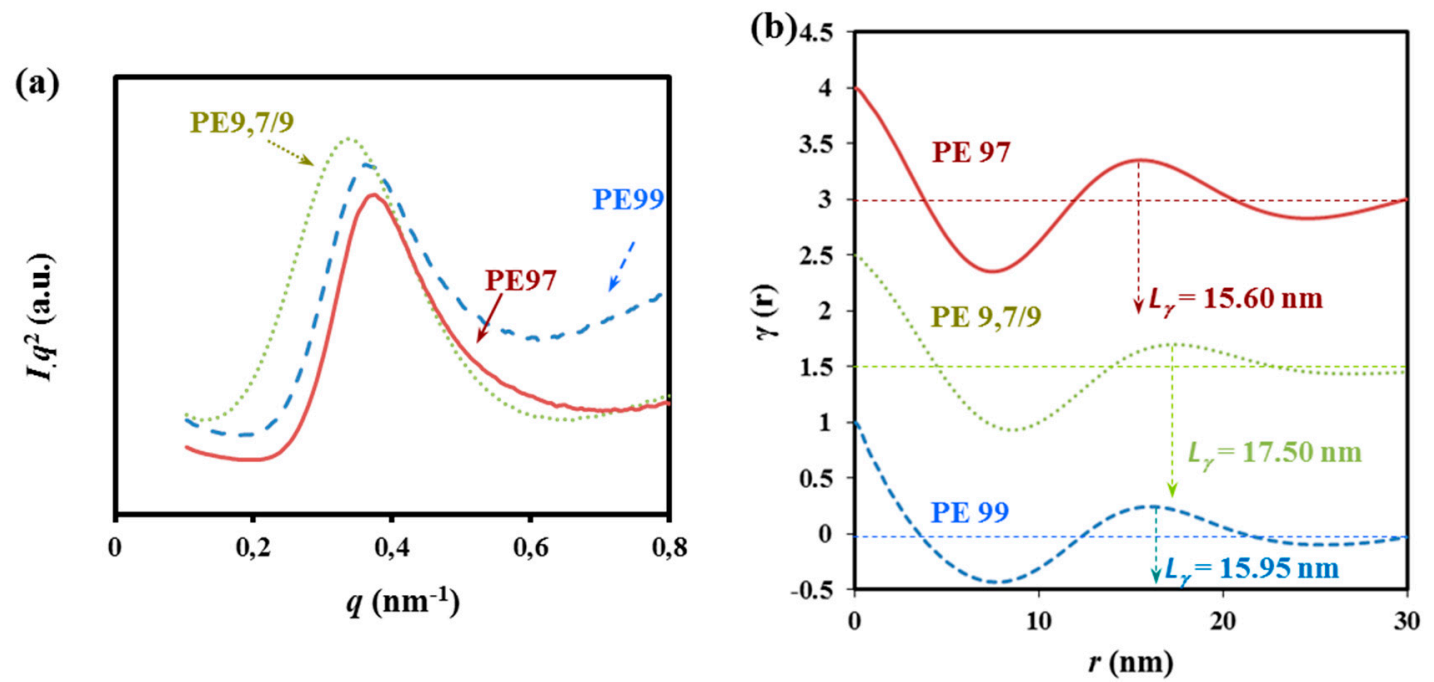

Figure 14. SAXS profiles (a) and corresponding correlation functions (b) for non-isothermally crystalized PES 9,7, PES 9,9, and COPES 9,7/9 samples.

The SAXS long period peak is clearly seen at a value of the scattering vector, $q=2 \pi \sin \theta / \lambda$, in the $0.35-0.38 \mathrm{~nm}^{-1}$ range after subtraction of the empty sample background observed near the beam stop. This peak, which can be attributed to the lamellar structure of the spherulites, revealed clear differences 
between the lamellar thicknesses of the three samples, the highest and lowest values corresponding to COPES 9,9/7 and PES 9,7, respectively.

Normalized one-dimensional correlation function [39,40], $\gamma(r)$, was calculated from Equation (1) and by considering extrapolations to low and high $q$ values by using Vonk's model and Porod's law, respectively.

$$
\gamma(r)=\int_{0}^{\infty} q^{2} I(q) \cos (q r) d q / \int_{0}^{\infty} q^{2} I(q) d q
$$

Correlation functions calculated for the three samples from SAXS profiles are shown in Figure 14b. In all cases, the $r$ values of the first maximum, $L_{\gamma}$, were close to twice the value of the first minimum, suggesting a narrow distribution of the layer widths of the major component (i.e., the crystal phase). Clear differences were found in the long period values between the copolymer $(17.50 \mathrm{~nm})$ and the two homopolymers (15.95 and $15.60 \mathrm{~nm}$ for PES 9,9 and PES 9,7, respectively).

Analyses of the correlation function also verifies that changes on the amorphous layer thickness were more significant. Specifically, 7.17, 6.24 and $4.25 \mathrm{~nm}$ were calculated for COPES 9,7/9, PES 9,7, and PES 9,9 samples, respectively. Crystallization of PES 9,7 and PES 9,9 homopolymers was also characterized by well differentiated $l_{c}$ and $l_{a}$ values despite that the crystals had similar long periods. In particular, higher and lower $l_{c}$ and $l_{a}$ thicknesses were determined for PES 9,9 (i.e., 11.7 and $4.25 \mathrm{~nm}$ ), which means a considerably higher crystallinity within the lamellar stacks. These crystallinities, $X_{c}^{\mathrm{SAX}}$, can be calculated as $l_{c} / L_{\gamma}$ which results in 0.74 and 0.60 for PES 9,9 and PES 9,7, respectively. It seems therefore that irregular molecular folds on the lamellar surface should involve larger segments when the polymer is constituted by the slightly more rigid pimelate units.

The greatest amorphous layer thickness was observed for the copolymer, indicating that chain defects caused by the presence of comonomer units could be placed in the amorphous interlamellar regions. Similar $X_{c}{ }^{\text {SAXS }}$ values were found for PES 9,7 and COPES 9,7/9 samples (i.e., 0.60 and 0.59, respectively) since the difference between the amorphous layer thickness was compensated by the lower crystalline lamellar thickness of the homopolymer. Results suggest that crystallization of COPES 9,7/9 should start by arrangement of the azelate rich moieties and therefore the pimelate units seem to be mainly incorporated as defects in the interlamellar amorphous region giving rise to the observed increase in the corresponding spacing. In fact, and as explained above, FTIR spectra revealed also that crystalline bands associated with PES 9,9 were predominant in the copolymer sample.

\section{Conclusions}

Poly(nonamethylene pimelate) and poly(nonamethylene azelate) crystallize according to an orthorhombic $P 2{ }_{1} a b$ space group and unit cells with parameters $a=0.500 \mathrm{~nm}, b=1.480 \mathrm{~nm}$ and $c$ (chain axis $)=2.25$ or $2.50 \mathrm{~nm}$. Molecules adopt an all-trans conformation and the packing is defined by a setting angle with respect to the $a$ axis close to $\pm 50^{\circ}$. Therefore, the crystalline structure is similar to other polyesters constituted by long diol and dicarboxylate units. It should be pointed out that large unit cells that incorporate several molecular segments are observed as has recently been postulated for different even-even polyesters. On the other hand, the chain axis periodicity corresponds to only one repeat unit in disagreement with odd-even and even-odd polyesters that require two units. Morphology of lamellar crystals is variable and specifically the aspect ratio increases as the degree of supercooling decreases. 
Copolymers having an equimolar ratio of pimelic and azelaic units are able to crystallize giving rise to well-formed lamellae and a molecular packing similar to that found in the related homopolymers. Nevertheless, a slight disorder along the chain axis can be deduced from the poorer X-ray fiber diffraction patterns. In any case, the crystalline phase of the copolymer is mainly constituted by azelate units as could be deduced from both, X-ray diffraction data and FTIR spectroscopy. Pimelate units are on the contrary mainly located in the lamellar folding surface giving rise to an increase of both, the lamellar long period and the amorphous layer thickness as well as a significant decrease in the crystallinity of the lamellar stacks.

Single crystals of the three studied samples were easily degraded by enzymes, which initiated the attack on the amorphous lamellar surfaces in such a way that the crystals edges remained practically unaltered until the late stages of degradation. The crystal edges were also more stable during the annealing processes performed in the crystallization medium at temperatures close to dissolution. Unusual framed crystals with rhombic and hexagonal morphologies can be obtained by this thermal treatment.

\section{Acknowledgments}

Authors are in debt to supports from MINECO and FEDER (MAT2012-36205) and the Generalitat de Catalunya (2009SGR1208). Diffraction experiments were performed at NCD beamline at ALBA Synchrotron with the collaboration of ALBA staff.

\section{Author Contributions}

Angélica Diáz performed the experiments; María Teresa Casas and Jordi Puiggalí directed the research; Jordi Puiggalí wrote the manuscript. All authors discussed the results and edited the manuscript.

\section{Conflicts of Interest}

The authors declare no conflict of interest.

\section{References}

1. Shirahama, H.; Kawaguchi, Y.; Aludin, M.S.; Yasuda, H. Synthesis and enzymatic degradation of high molecular weight aliphatic polyesters. J. App. Polym. Sci. 2001, 80, 340-347. [CrossRef]

2. Fujimaki, T. Processability and properties of aliphatic polyesters, 'BIONOLLE', synthesized by polycondensation reaction. Polym. Degrad. Stab. 1998, 29, 209-214. [CrossRef]

3. Tserki, V.; Matzinos, P.; Pavlidou, E.; Panayiotou, C. Biodegradable aliphatic polyesters. Part II. Synthesis and characterization of chain extended poly(butylene succinate-co-butylene adipate). Polym. Degrad. Stab. 2006, 91, 377-384. [CrossRef]

4. Takasu, A.; Ishii, M.; Inai, Y.; Hirabayashi, T.; Inomata, K. Threo-disyndiotactic polymerization of $(E, E)$-alkyl sorbates assisted by bulky organoaluminum lewis acid via "alternating turning over polymerization (ATOP)" mechanism. Macromolecules 2003, 36, 7055-7064. [CrossRef] 
5. Takasu, A.; Iio, Y.; Oishi, Y.; Narukawa, Y.; Hirabayashi, T. Environmentally benign polyester synthesis by room temperature direct polycondensation of dicarboxylic acid and diol. Macromolecules 2005, 38, 1048-1050. [CrossRef]

6. Sokolsky-Papkova, M.; Langerb, R.; Domb, A.J. Synthesis of aliphatic polyesters by polycondensation using inorganic acid as catalyst. Polym. Adv. Technol. 2011, 22, 502-511. [CrossRef] [PubMed]

7. Sugihara, S.; Toshima, K.; Matsumura, S. New strategy for enzymatic synthesis of high-molecular-weight poly(butylene succinate) via cyclic oligomers. Macromol. Rapid Commun. 2006, 27, 203-207. [CrossRef]

8. Habeych, D.I.; Eggink, G.; Boeriu, C.G. Linear and cyclic ester Oligomers of succinic acid and 1,4-butanediol: Biocatalytic synthesis and characterization. Biocat. Biotrans. 2011, 29, 299-310. [CrossRef]

9. Díaz, A.; Katsarava, R.; Puiggalí, J. Synthesis, properties and applications of biodegradable polymers derived from diols and dicarboxylic acids: From polyesters to poly(ester amide)s. Int. J. Mol. Sci. 2013, 15, 7064-7123. [CrossRef] [PubMed]

10. Quinzler, D.; Mecking, S. Linear semicrystalline polyesters from fatty acids by complete feedstock molecule utilization. Angew. Chem. Int. Ed. 2010, 49, 4306-4308. [CrossRef] [PubMed]

11. Stempfle, F.; Quinzler, D.; Heckler, I.; Mecking, S. Long-chain linear C19 and C23 monomers and polycondensates from unsaturated fatty acid esters. Macromolecules 2011, 44, 4159-4166. [CrossRef]

12. Yang, Y.; Lu, W.; Zhang, X.; Xie, W.; Cai, M.; Gross, R.A. Two-step biocatalytic route to biobased functional polyesters from $\omega$-carboxy fatty acids and diols. Biomacromolecules 2010, 11, 259-268. [CrossRef] [PubMed]

13. Hojabri, L.; Kong, X.; Narine, S.S. Functional thermoplastics from linear diols and diisocyanates produced entirely from renewable lipid sources. Biomacromolecules 2010, 11, 911-918. [CrossRef] [PubMed]

14. Gan, Z.; Abe, H.; Doi, Y. Biodegradable poly(ethylene succinate) (PES). 1. Crystal growth kinetics and morphology. Biomacromolecules 2000, 1, 704-712. [PubMed]

15. Gan, Z.; Abe, H.; Doi, Y. Biodegradable poly(ethylene succinate) (PES). 2. Crystal morphology of melt-crystallized ultrathin film and its change after enzymatic degradation. Biomacromolecules 2000, 1, 713-720. [CrossRef] [PubMed]

16. Gan, Z.; Abe, H.; Doi, Y. Crystallization, melting, and enzymatic degradation of biodegradable poly(butylene succinate-co-14 mol ethylene succinate) copolyester. Biomacromolecules 2001, 2 , 313-321. [CrossRef] [PubMed]

17. Mochizuki, M.; Mukai, K.; Yamada, K.; Ichise, N.; Murase, S.; Iwaya, Y. Structural effects upon enzymatic hydrolysis of poly(butylene succinate-co-ethylene succinate)s. Macromolecules 1997, 30, 7403-7407. [CrossRef]

18. Li, X.; Hong, Z.; Sun, J.; Geng, Y.; Huang, Y.; An, H. Identifying the phase behavior of biodegradable poly(hexamethylene succinate-co-hexamethylene adipate) copolymers with FTIR. J. Phys. Chem. 2009, 113, 2695-2704. [CrossRef] [PubMed] 
19. Li, X.; Sun, J.; Huang, Y.; Geng, Y.; Wang, X.; Ma, Z.; Shao, C.G.; An, H.N.; Yan, T.Z.; Li, L.B. Inducing new crystal structures through random copolymerization of biodegradable aliphatic polyester. Macromolecules 2008, 41, 3162-3168. [CrossRef]

20. Liang, Z.; Pan, P.; Zhu, B.; Dong, T.; Hua, L.; Inoue, Y. Crystalline phase of isomorphic poly(hexamethylene sebacate-co-hexamethylene adipate) copolyester: Effects of comonomer composition and crystallization temperature. Macromolecules 2010, 43, 2925-2932. [CrossRef]

21. Liang, Z.; Pan, P.; Zhu, B.; Inoue, Y. Isomorphic crystallization of aliphatic copolyesters derived from 1,6-hexanediol: Effect of the chemical structure of comonomer units on the extent of cocrystallization. Polymer 2011, 52, 2667-2676. [CrossRef]

22. Ueda, A.S.; Chatani, Y.; Tadokoro, H. Structural studies of polyesters. IV. Molecular and cristal structures of poly(ethylene succinate) and poly(ethylene oxalate). Polym. J. 1971, 2, 387-397. [CrossRef]

23. Minke, R.; Blacwell, J. Single crystals of poly(tetramethylene adipate). J. Macromol. Sci. B Phys. 1980, 18, 233-255. [CrossRef]

24. Aylwin, P.A.; Boyd, R.H. Aliphatic polyesters as models for relaxation processes in crystalline polymers: 1. Characterization. Polymer 1984, 25, 323-329. [CrossRef]

25. Kanamoto, T.; Tanaka, K. Growth and morphology of single crystals of linear aliphatic polyesters. J. Polym. Sci. Part A 1971, 9, 2043-2060. [CrossRef]

26. Almontassir, A.; Gestí, S.; Franco, L.; Puiggalí, J. Molecular packing of polyesters derived from 1,4-butanediol and even aliphatic dicarboxylic acids. Macromolecules 2004, 37, 5300-5309. [CrossRef]

27. Gestí, S.; Almontassir, A.; Casas, M.T.; Puiggalí, J. Molecular packing and crystalline morphologies of biodegradable poly(alkylene dicarboxylate)s derived from 1,6-hexanediol. Polymer 2004, 45, 8845-8861. [CrossRef]

28. Gestí, S.; Almontassir, A.; Casas, M.T.; Puiggalí, J. Crystalline structure of poly(hexamethylene adipate). Study on the morphology and the enzymatic degradation of single crystals. Biomacromolecules 2006, 7, 799-808. [CrossRef] [PubMed]

29. Gestí, S.; Casas, M.T.; Puiggalí, J. Crystalline structure of poly(hexamethylene succinate) and single crystal degradation studies. Polymer 2007, 48, 5088-5097. [CrossRef]

30. Iwata, T.; Doi, Y. Morphology and enzymatic degradation of poly( $\varepsilon$-caprolactone) single crystals: Does a polymer single crystal consist of micro-crystals? Polym. Int. 2002, 51, 852-858. [CrossRef]

31. Iwata, T.; Doi, Y. Morphology and enzymatic degradation of poly(L-lactic acid) single crystals. Macromolecules 1998, 31, 2461-2467. [CrossRef]

32. Iwata, T.; Doi, Y. Morphology and enzymatic degradation of solution-grown single crystals of poly(ethylene succinate). Macromolecules 2001, 34, 7343-7348. [CrossRef]

33. Iwata, T.; Kobatashi, S.; Tabata, K.; Yonezawa, N.; Doi, Y. Crystal structure, thermal behavior and enzymatic degradation of poly(tetramethylene adipate) solution-grown chain-folded lamellar crystals. Macromol. Biosci. 2004, 4, 296-307. [CrossRef] [PubMed]

34. Casas, M.T.; Puiggalí, J. Enzymatic degradation of poly(octamethylene suberate) lamellar crystals. Polym. Degrad. Stab. 2009, 94, 1941-1947. [CrossRef]

35. Cerius2; Accelrys Inc.: Cambridge, UK, 2002. 
36. Bassett, D.C.; Keller, A. On the habits of polyethylene crystals. Philos. Mag. 1962, 7, 1553-1584. [CrossRef]

37. Girolamo, M.; Keller, A.; Stejny, J. Single crystals of linear polyesters. Makromol. Chem. 1975, 176, 1489-1502. [CrossRef]

38. Furuhashi, M.; Iwata, T.; Sikorski, P.; Atkins, E.; Doi, Y. Structure and morphology of the aliphatic polyester poly- $\beta$-propiolactone in solution-grown chain-folded lamellar crystals. Macromolecules 2000, 33, 9423-9431. [CrossRef]

39. Vonk, C.G.; Kortleve, G. X-ray small-angle scattering of bulk polyethylene. Kolloid-Z. Z. Polymere 1967, 220, 19-24. [CrossRef]

40. Vonk, C.G. A general computer program for the processing of small-angle X-ray scattering data. J. Appl. Cryst. 1975, 8, 340-341. [CrossRef]

(C) 2015 by the authors; licensee MDPI, Basel, Switzerland. This article is an open access article distributed under the terms and conditions of the Creative Commons Attribution license (http://creativecommons.org/licenses/by/4.0/). 